\title{
Genetics, immunology and biomarkers in clinical practice: do they assist in clinical management?
}

\section{P. L. LAKATOS}

\section{INTRODUCTION}

In recent decades there has been a change in the epidemiology of inflammatory bowel diseases (IBD) in North America, as well as Western, and some Eastern European countries ${ }^{1-3}$. Both Crohn's disease (CD) and ulcerative colitis (UC) possibly stem from common mechanisms, while the exact aetiology remains unknown ${ }^{4}$.

Nowadays a generally accepted hypothesis is that UC and CD may develop from a dysregulated response of the mucosal immune system towards microbial antigens in genetically predisposed individuals. IBD are identified as multifactorial, polygenic diseases with probable genetic heterogeneity. According to this hypothesis, different genetic backgrounds may explain the various clinical patterns of the disease $\mathrm{e}^{4,5}$. In addition to genetic predisposition, various environmental and host factors (e.g. genetic, epithelial, immune, and non-immune) play a major role in the pathogenesis of IBD. Extensive heterogeneity is observed in terms of presentation, extraintestinal manifestations, and location of $\mathrm{CD}$, while behaviour and response to treatment are heterogeneous in both $\mathrm{CD}$ and $\mathrm{UC}^{6}$. Furthermore, it is now undisputed that enteric bacterial flora plays a key role in the pathogenesis of IBD, both in UC and CD. Nonetheless, the exact mechanism by which the intestinal mucosa loses tolerance for its bacterial neighbours remains elusive.

According to the traditional view on the pathogenesis of IBD, intestinal inflammation is mediated by the acquired immune system. The chronic inflammation could result from an overly aggressive activity of effector lymphocytes and proinflammatory cytokines, which may overcome the control mechanisms. Alternatively, IBD may result from a primary failure of regulatory lymphocytes and cytokines, such as interleukin 10 (IL-10) and transforming growth factor beta $(\mathrm{TGF}-\beta)$, to control inflammation and 
effector pathways. In addition, an important mechanism in CD is the resistance of $\mathrm{T}$ cells to apoptosis after activation. Recently, this hypothesis has been challenged, in part, based on the results of genetic studies. The equally important role of the host's genetic regulation of the innate immune response in the pathogenesis of CD has been brought to sharp focus by the identification of the role of the NOD2 (CARD15) gene by three independent groups in 2001. As a consequence, novel genetic determinants of susceptibility and phenotype are currently being widely investigated by genome-wide scanning and studies of positional, and possibly functional, candidate genes in identified susceptibility regions of certain chromosomes (loci) ${ }^{7}$.

Furthermore, currently no simple diagnostic laboratory tool exists for diagnosing IBD. Biological markers that are potentially useful in IBD include proteins of inflammation such as C-reactive protein (CRP), fecal calprotectin, and several antibodies. Nonetheless, these biomarkers have many limitations. The role of the various antibodies in the current IBD diagnostic algorithm is often questioned due to their limited sensitivity ${ }^{8}$. In contrast, the association of serological markers with disease behaviour and phenotype is becoming increasingly well established, while other markers (e.g. CRP, EXR, calprotectin) are mainly helpful in assessing disease activity and predicting relapse.

Finally, the sequence of immunological events underlying the inflammatory reaction in IBD is extremely complex and involves both the innate and antigendriven adaptive immune systems. Evidence indicates that dysregulation of mucosal immunity in the gut of IBD patients leads to altered production of inflammatory cytokines (e.g. tumour necrosis factor alpha (TNF- $\alpha$ ), IL-1, -2, $4,-5,-10,-12$, and more recently IL-17 and IL-23) and trafficking of effector leukocytes into the bowel (see Figure 1). The latter mechanism culminates in uncontrolled intestinal inflammation. Novel biological therapies are directed against several key players in this cascade. Major targets for such treatment include inflammatory cytokines and their receptors, as well as adhesion molecules. Blockade of T-cell proliferation and activation, and inhibition of Tcell-derived cytokines, has been most extensively targeted by clinical trials in humans in both CD and UC. Inhibition of adhesion molecules and the use of selected growth factors also seem to have a therapeutic potential. In addition, restoration of regulatory $\mathrm{T}$-cell and dendritic-cell functions is still pending further investigation in clinical trials. Thus, recent advances in understanding the immunological events of IBD have led to the discovery of novel targets of biological therapy directed against several key participants involved in the inflammatory cascade.

Since a detailed presentation of the mechanisms involved would go beyond the scope of this review, and the clinical importance in everyday practice is discussed above, we will focus on emerging data concerning the genetics, genotype-phenotype associations as well as data available on biomarkers for the diagnosis and prediction of disease course in IBD. By assessing these markers we strive for an objective measurement of disease activity as symptoms may often be subjective; and secondly, to possibly avoid invasive (endoscopic) procedures that are often a burden on the patient. In this review we attempt to answer the following questions: 
GENETICS, IMMUNOLOGY AND BIOMARKERS IN CLINICAL PRACTICE

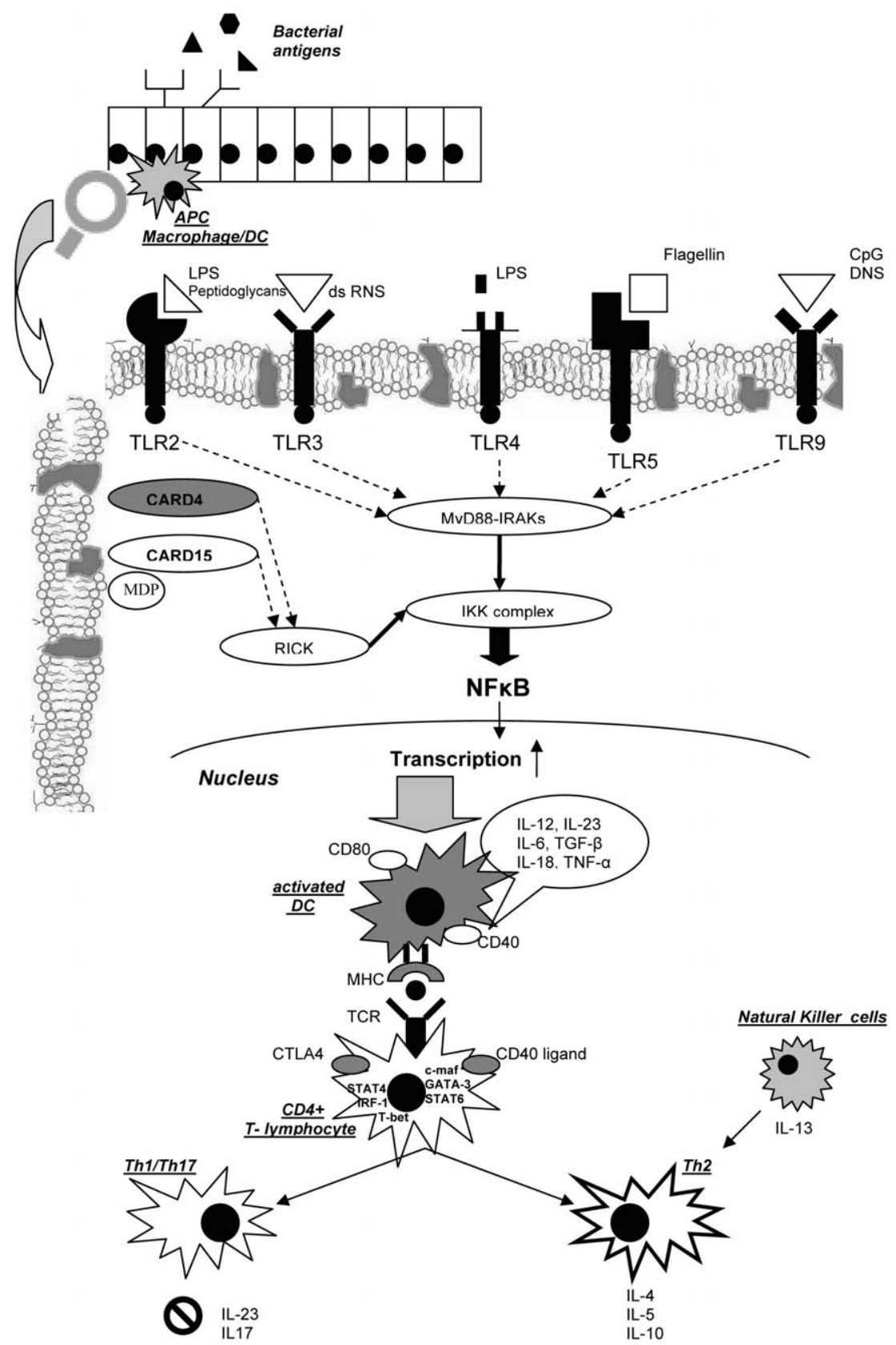

Figure 1 Pathogenesis of IBD (modified after ??)

$\mathrm{Q}$ to $\mathrm{A}$ : Which reference is this? 
1. Is genetic investigation and detection of biomarkers helpful in the diagnosis of symptomatic IBD patients?

2. Is genetic testing indicated in clinically unaffected family members to identify patients at higher risk who might require 'preventive measures'?

3. Do genetic tests and biomarkers help in further classifying indeterminate colitis patients?

4. Can genetic tests and biomarkers help in predicting disease phenotype and progression (e.g. location, behaviour in $\mathrm{CD}$, extraintestinal manifestations, need for surgery)?

5. Do genetic tests and biomarkers help in predicting relapse or response and side-effects of medical therapy, that is, do they help in 'individualizing' the treatment?

\section{GENETICS}

To this date, a total of nine loci have been found to be associated with IBD, having specific linkage requirements, and were subsequently labeled as IBD $1-9^{5}$ (see Table 1). Furthermore, it is clear that some loci correlate with either UC or $\mathrm{CD}$, while others are involved in the pathogenesis of both IBD forms.

Table 1 Locations of nine major loci showing linkage to inflammatory bowel disease (modified Q to A: reference? after ??)

\begin{tabular}{|c|c|c|c|}
\hline IBD locus & Chromosome & Identified genes & Disease \\
\hline \multirow[t]{2}{*}{$\begin{array}{l}\text { IBD1 } \\
\text { IBD2 }\end{array}$} & $\begin{array}{l}16 q 13 \\
12 q 14\end{array}$ & $\begin{array}{l}\text { NOD2/CARD15 } \\
\text { Not known }\end{array}$ & $\mathrm{CD}$ \\
\hline & & $\begin{array}{l}\text { (VDR, NRAMp2, MMP18, } \\
\beta_{2} \text {-integrin) }\end{array}$ & $\mathrm{UC}$ \\
\hline IBD3 & $6 \mathrm{p}$ & $\begin{array}{l}\text { Not known } \\
\text { (HLA, TNF) }\end{array}$ & IBD \\
\hline IBD4 & $14 q 11-12$ & $\begin{array}{l}\text { Not known } \\
\text { (TCR, LTB4 receptor) }\end{array}$ & $\mathrm{CD}$ \\
\hline IBD5 & $5 q 31-33$ & $\begin{array}{l}\text { SLC22A4/A5 } \\
\text { (IRGM, IL-4, 6, CD14) }\end{array}$ & $\mathrm{CD}$ \\
\hline IBD6 & $19 \mathrm{p} 13$ & $\begin{array}{l}\text { Not known } \\
\text { (ICAM1, C3, TBXA2) }\end{array}$ & IBD \\
\hline IBD7 & $1 \mathrm{p} 36$ & $\begin{array}{l}\text { Not known } \\
\text { (TNF-R family, IL-23R) }\end{array}$ & IBD, UC \\
\hline IBD8 & $16 \mathrm{p} 12$ & Not known & $\mathrm{CD}$ \\
\hline \multirow[t]{3}{*}{ IBD9 } & $3 \mathrm{p} 26$ & $\begin{array}{l}\text { Not known } \\
\text { (CCR5, CCR9, hMLH1) }\end{array}$ & IBD \\
\hline & $10 \mathrm{q} 23$ & DLG5 & IBD \\
\hline & $2 q 37$ & ATG16L1 & $\mathrm{CD}$ \\
\hline
\end{tabular}




\section{Genes involved in the recognition of bacteria}

\section{NOD2/CARD15}

Gene-protein function: In 2001 the identification of NOD2 (nucleotide oligomerization domain)/CARD15 (caspase activation recruitment domain) on chromosome 16 in the IBD1 region, as a candidate gene for $\mathrm{CD}^{9,10}$, has stimulated further research focusing on novel genetic determinants of susceptibility and phenotype in IBD.

The identification of NOD2/CARD15 is of great importance in understanding the pathogenesis of IBD, especially CD, as NOD2/CARD15 is an intracellular element responsible for the indirect recognition of bacterial peptidoglycan through the binding of muramyl dipeptide ${ }^{11,12}$. The function of the immune system enables it to recognize a vast number of antigens that are present in our environment (and in the gut), to mount an appropriate response as well as limit the inflammatory and immune responses elicited by different pathogens. NOD2/CARD15 serves as direct evidence that dysregulation in the immune system and recognition of bacteria can lead to immune-mediated diseases through uncontrolled inflammatory processes.

The most intriguing question that remains to be answered concerns the mechanism whereby mutations in the NOD2/CARD15 gene predispose towards the chronic intestinal inflammation characteristic of CD. Gain-offunction and loss-of-function mechanisms were both reported (e.g. increased permeability, activation of NF- $\mathrm{NB}$, regulation of Paneth cells' degranulation, regulation of TLR2 stimulation by peptidoglycans). Interestingly, mice lacking NOD2 or possessing mutated NOD2 variants do not spontaneously develop CD. Together, these data suggest that NOD2 mutations, rather than having a direct causative role in disease development, create an intestinal environment favourable for $\mathrm{IBD}^{13}$, for instance, via decreased expression of $\alpha$ - and $\beta$ defensins, thus influencing the innate immunity.

Disease susceptibility and genotype-phenotype association: Three major mutations were identified within NOD2/CARD15: one frameshift (3020insC, SNP13) and two missense mutations (R702W-SNP8 and G908R-SNP12).

The presence of a NOD2/CARD15 mutation increases the risk for CD by 1.4-4.3-fold in heterozygous patients and 17.6-44.0-fold in homozygous and compound heterozygous patients. Of importance, reports exist of homozygous individuals who are disease-free ${ }^{14}$. It is estimated that any of these three common mutations, involving NOD2/CARD15, are present in a heterozygous form in $30-50 \%$ of $C D$ patients and $7-20 \%$ of controls from North America and Europe ${ }^{15-18}$. However, various geographical differences were noted: a much lower prevalence of these mutations was reported in, for example, African American, Chinese ${ }^{19}$ and Japanese ${ }^{20}$ populations. The prevalence was also lower in other northern European countries ${ }^{21}$. New evidence from association studies in healthy populations and disease indices, however, suggests that CARD15/NOD2 rather interacts with other, unknown risk cofactors ${ }^{22}$. 
The three common NOD2/CARD15 mutations were associated with ileal disease and fibrostenosing behaviour. On the contrary, in colonic and fistulous disease, they were relatively less frequent ${ }^{10,23,24}$. The mutations were not associated with UC. In CD the population attributable risk for ileal disease is determined, in $40 \%$, by NOD2/CARD 15 and in $20 \%$ by HLA genes; the numbers are similar for ileocolonic disease (NOD2/CARD15: 30\%, HLA: $40 \%$, while colonic disease is thought to be associated with HLA and other, still unknown, genes ${ }^{23}$.

\section{NOD1/CARD4}

A protein that is structurally and functionally similar to NOD2/CARD15, the NOD1/CARD4, is located on chromosome $7 \mathrm{p}$ and translates into an intracellular bacterial pathogen-associated molecular pattern ${ }^{25}$. Of particular interest is its location in the midst of a region with strong IBD correlation, being translated.

Conflicting data are available concerning NOD1/CARD4. Zouali et al. investigated the role of protein in 63 IBD patients. Eleven exons of the NOD1/CARD4 gene were screened for polymorphisms. Indeed, several variants were identified, none of which, according to the researchers, proved any association with IBD $^{26}$. In contrast, a more recent publication by

$\mathrm{Q}$ to A: no reference for McGovern provided
McGovern et al. located a complex insertion/deletion allele on NOD1, associating it with an early onset of IBD as well as extraintestinal manifestations.

\section{Toll-like receptors and CD14}

Gene-protein function: Toll-like receptors (TLR) expressed in myeloid cells play a major role both in detecting microbes (lipopolysaccharide) and in initiating the innate immune response. Accordingly, a disturbance in their function predisposes to infections with Gram-negative bacterial pathogens ${ }^{27,28}$. TLR may also influence the nature of the immune response, in particular by skewing $\mathrm{T}$ cells towards a Th1 or Th2 profile ${ }^{29}$.

Disease susceptibility and genotype-phenotype association: IBD is characterized by an altered expression pattern of TLR on the surface of intestinal epithelium, with TLR4 expression found to be up-regulated in patients with CD. In contrast, the expression of TLR 2 and TLR 5 is unchanged, while TLR3, which recognizes viral replication, is down-regulated ${ }^{30}$. The D299G (Asp299Gly) polymorphism of the TLR4 gene is associated with LPS hyporesponsiveness ${ }^{31}$ and was found to also be associated with CD (OR 2.45-2.80) and UC (OR $2.05)$ in the study by Franchimont et al. ${ }^{27}$, as well as in Greek ${ }^{32}$ and German studies $^{33}$. However, results are conflicting, as other studies failed to replicate this association ${ }^{18,34}$.

A recent study by a Belgian group ${ }^{35}$ investigated 35 SNP in the TLR1-10 genes. Although none of the SNP were involved in disease susceptibility to either CD or UC, a positive association between TLR1 R80T and pancolitis in UC (OR 2.8) was found. The TLR2 R753G SNP was also associated with 
pancolitis (OR 4.7). Additionally, there was a negative association between TLR6 S249P and UC with proctitis only (OR 0.22). In CD a negative association was found between ileal disease involvement and TLR1 S602I (OR 0.52).

Conflicting data have emerged on the association between the bacterial receptor CD14 and IBD. Klein et al. found the 159TT genotype to be associated with $\mathrm{CD}$ but not with $\mathrm{UC}^{36}$. In a Japanese study ${ }^{37}$ the same genotype was associated with UC (OR 1.96) but not with CD, and an additional study investigating Caucasian patients failed to demonstrate any association $^{38}$.

\section{Mucosal integrity and transport}

\section{SLC22A4/OCTN1, SLC22A5/OCTN2, and OCTN3}

Gene-protein function: One of the novel findings in IBD genetics in 2004 was the identification of SLC22A4/OCTN1 and SLC22A5/OCTN2 genes coding for integral membrane proteins. The proteins' functions were found to be multispecific and served as bidirectional transmembrane transporters of carnitine and organic cations ${ }^{39}$. Variant alleles are associated with functional changes: the SLC22A4 variant decreases carnitine, but augments organic cation transporter activity, while the SLC22A5 variant impairs heat shock protein-driven promoter transcriptional activation ${ }^{42}$. Another possibility is that the enhanced cation transporter activity of the OCTN1 L503F variant may provoke disease by allowing aberrant uptake of toxic substrates.

Disease susceptibility and genotype-phenotype association: The association between $5 \mathrm{q} 31$ and CD was first noted in genome-wide screens (the genes for Th2 cytokines - e.g. IL-3, $-4,-5,-9,-13$, and IRF1 map to this region). The risk haplotype is associated with only a moderate risk for CD (OR 1.4-1.5). The effect of NOD2/CARD15 was additive; however, the 5q31 haplotype was found to be an independent risk factor ${ }^{40,41}$. In a German study it was also associated with UC. Nonetheless, data support significant geographical heterogeneity as no association was found between the IBD5 haplotype and clinical presentation, nor was it correlated with IBD in a Japanese study ${ }^{41}$. Based on data available in the literature, IBD5 mainly increases the overall risk for IBD, whereas NOD2/CARD15 mutations are primarily responsible for the determination of phenotype.

The SLC22A4 C1672T and the SLC22A5 promoter G207C variants increased the risk for $\mathrm{CD}$ by $2-2.5$-fold when present as a single copy and by 4-fold in homozygous carriers ${ }^{42,43}$. The elevated risk, attributed to the OCTN TC haplotype and NOD2/CARD15 mutations, was additive with an odds ratio of 7.3-10.5 in double carriers. In a more recent Japanese study of several different SLC22A4/A5 and DLG5 polymorphisms and CD, a weak, or even no, association $^{44}$ was found with very low prevalence of variant alleles, concurring with the Ashkenazi population ${ }^{45}$, where the frequency of the allele was also low, indicating racial differences. 
In contrast, in a recent study by Vermeire et al. ${ }^{46}$, encompassing 981 patients, no association was found between any OCTN/DLG5 variants and IBD. In this study the OCTN TC risk haplotype was associated with penetrating disease (OR 1.474, 95\% CI 1.028-2.114; $p=0.035$ ). In a German study ${ }^{43}$ the TC haplotype was associated with non-fistulizing non-fibrostenotic disease (OR 1.57), colonic disease (OR 1.31), an earlier age at the onset of disease, and reduced need for surgery (OR 1.38).

\section{DLG5}

DLG5 is a member of the MAGUK (membrane-associated guanylate kinase) gene family, which encodes cell scaffolding proteins and is also involved in the maintenance of epithelial integrity and regulation of cell growth ${ }^{47}$. This latter role is potentially impaired by expression of the CD-associated DLG5 variants causing increased permeability and disease.

The impact on the overall risk of developing IBD is much smaller compared to NOD2/CARD15. The association between DLG5 (Drosophilia discs large homolog 5) at chromosome 10q22-23 was first reported by Stoll et al. ${ }^{48}$, who showed that the DLG R30Q allele was overtransmitted to individuals with IBD (transmitted/non-transmitted, 90/73; $p=0.09$ ) and CD (transmitted/nontransmitted, 58/43; $p=0.065)$. In a joint Canada-UK study Daly et al. ${ }^{49}$ could replicate the association between R30Q and IBD in a Canadian/Italian case-control cohort; however, the association was not found in another casecontrol cohort from the UK. Nonetheless, the risk attributed to the variant allele was estimated to be modest (in the vicinity of 1.25). An interaction between DLG5 and NOD2/CARD15 was also detected.

This interaction, however, was not replicated by the same group in English and Scottish CD patients or by recent publications from Germany ${ }^{43,50}$, Belgium $^{46}$, Norway ${ }^{21}$ ) and by our group that investigated 773 Hungarian IBD patients $^{51}$. In the Belgian study, overtransmission of the wild-type allele and undertransmission of the variant 113A allele was reported. The same tendency was observed in the Hungarian patients: a protective effect for the $113 \mathrm{~A}$ variant allele carriers (OR $0.67,95 \%$ CI $0.45-1.013 ; p=0.06$ ), Thus, the contribution of this gene to disease susceptibility, if any, is relatively minor. No genotypephenotype associations were found in the studied populations ${ }^{50,51}$.

\section{CYTOKINES, MULTIDRUG RESISTANCE AND OTHER GENE POLYMORPHISMS}

Although much is known about the immune mechanisms involved in the interaction between non-pathogenic, commensal bacteria and pathogenic species, and the control of local inflammatory changes, a lack of reproducibility has challenged many of the other reported genotypephenotype associations in IBD, such as the association between interleukin polymorphisms and IBD.

The association between a low-producing allele, allele 2 of the interleukin (IL)-1RA gene and UC (OR 1.3), extensive colitis, and the need for 
colectomy $^{52,53}$ was reported in a Caucasian population. On the contrary, another study investigating 529 IBD patients failed to confirm these results ${ }^{54}$. Results on IL-10 and IL-18 polymorphisms are also contradictory.

In addition, an association was reported between microsatellite loci of TNF$\alpha$ and $C^{55}$. Recently the TNF receptor (TNFR) SF1A was reported to be associated with $\mathrm{CD}^{56}$ and was less prevalent in stricturing (OR 0.38) and colonic (OR 0.41) disease. Similarly, different TNF superfamily member 15 (TNFS15) haplotypes were associated with CD in Japanese patients (OR 2.15$3.23)^{57}$.

In 2003 Brant et al. described a suggestive linkage on chromosome 7q, containing the multidrug resistance (MDR)-1 gene, in association with the appearance of $\mathrm{UC}$ and $\mathrm{CD}^{58}$. This particular gene is a membrane transport protein with several documented human polymorphisms having effects on intestinal absorption and drug pharmacokinetics. In a German study the C3435T mutation, previously associated with a 50\% decreased protein secretion, but not the G2677T mutation, correlated with UC (OR 1.6-2.0). The association was strongest in extensive UC (OR 2.64) and severe disease (OR 1.67), yet it showed no manifestation in $\mathrm{CD}^{59,60}$. In a recent English study $^{61}$ six intronic variant SNP of MDR 1 (especially the intron 3 G-A SNP), showed a very significant association to UC, particularly in patients with extensive disease. However, data are conflicting, since a Spanish group reported that the C3435T CC genotype was associated with CD (OR 1.58) and no association was found in eastern European patients ${ }^{63}$.

\section{A DIFFERENT APPROACH}

The most recent studies used different methodology: instead of linkage and candidate gene analyses, broad SNP associations were investigated in genomewide scans. The new data identified additional pieces in the puzzle of IBD.

The importance of altered bacterial sensation is underlined by the finding that an independent association scan of 19779 non-synonymous SNP in 735 German CD cases and 368 controls has identified a significant association of an SNP in the autophagy-related 16-like 1 gene ATG16L1 on chromosome 2q37.1 with $C^{64}$. This SNP (rs2241880, T300A), which was associated with $\mathrm{CD}$ in two German panels and one British panel of $\mathrm{CD}$ patients $\left(\mathrm{OR}_{\text {heterozygous }}\right.$ 1.35-1.45; OR homozygous 1.71-1.77), was associated with CARD15. The association was not observed in a German panel of UC cases or trios, suggesting that it is specific to CD. The ATG16L1 protein is involved in the autophagocytosis pathway, which is known to mediate resistance to intracellular pathogens such as bacteria and viral particles ${ }^{65}$. Subsequent reports ${ }^{66,67}$ have confirmed the association between the variant allele and CD

Q to A: please provide as well as with ileal disease in one study; however, no evidence of interaction reference with CARD15, IL-23R, or IBD5 was found. Recently, an English group also reported an association between two SNP in the autophagy-inducing IRGM gene on chromosome 5q33.1 and CD in 2930 cases and 4962 controls. Variant SNP were associated with an OR of $1.36-1.38^{68}$. 
Recently, an association was reported between rare SNP of the IL-23R gene located on $1 \mathrm{q} 31^{69}$ and CD. The variant Arg381Gln allele was associated with decreased susceptibility for CD (OR 0.26 ). Similar results were reported in confirmatory studies (OR $0.38-0.65$ and $0.63-0.78$ ) for both CD and UC from the $\mathrm{UK}^{70,71}$. Preliminary evidence suggests an epistatic interaction with the IBD5 risk haplotype. No phenotype-genotype associations were discovered.

\section{PHARMACOGENETICS - THE ROLE OF GENETIC FACTORS IN PREDICTING THE SUCCESS OF THERAPY AND DRUG TOXICITY}

Individual response to drugs is a major problem in clinical practice. Pharmacogenetic research in IBD is developing in two directions: (1) the identification and design of possible new therapeutic targets by exploiting current knowledge of susceptibility genes - an area that is rapidly developing; and (2) examination of certain genomic areas that may be valuable in elucidating variations resulting in the lack of therapeutic benefit or adverse drug reactions, leading to a more personalized/individualized therapy. The fundamental principle underlying pharmacogenetic investigations is that variations in drug response may reflect functional differences in a gene product encoded by different alleles of the same gene. Factors may influence either pharmacodynamic (relating drug-target responsiveness at fixed drug concentrations) or pharmacokinetic (determining drug and metabolite concentrations, including absorption, distribution, metabolism, and elimination) characteristics. At the present time only limited information is available, much of it regarding the genetic basis of drug metabolism and elimination.

The genetic regulation of azathioprine/6-mercaptopurine (AZA/6-MP) metabolism has been widely studied and provides perhaps the best example of the clinical application of pharmacogenetics in IBD. Thiopurine $S$ methyltransferase (TPMT) limits the production of 6-thioguanines (6-TGN) by converting 6-MP to 6-thioruric acid and 6-methylmercaptopurine ${ }^{72}$, which may lead to myelotoxicity. Approximately $5 \%$ of the white population carries one or more variant TPMT alleles, with more than 10 variant alleles reported ${ }^{73}$. The functional consequences of alleles $* 2, * 2 \mathrm{~A}, * 3 \mathrm{~B}$, and $* 3 \mathrm{C}$, accounting together for more than $90 \%$ of mutant alleles, have been extensively characterized.

Population studies have shown that the distribution of TPMT activity is trimodal: $0.3-0.5 \%$ of the population has low to absent activity (TPMTL/ TPMTL), around $10 \%$ have intermediate activity (TPMTL/TPMTH), and approximately $90 \%$ inherit normal to high enzyme activity (TPMTH/ TPMTH $)^{74}$; as previously mentioned, a correlation has been observed between the TPMT genotype and enzyme activity. Carriage of two variant alleles was associated with deficient TPMT activity, whereas heterozygosity was associated with intermediate enzyme activity. These data suggest that genotyping might identify patients at high risk of haematological toxicity. Unfortunately, a number of factors currently limit the incorporation of TPMT genotyping into clinical practice. The principal limitation is that genotyping 
does not predict TPMT activity in all patients. Homozygosity or compound heterozygosity for TPMT variants is a well-known contraindication to AZA at conventional doses, as it causes early and profound bone marrow suppression.

Nevertheless, it is clear that there are many other causes of myelotoxicity. This was accurately demonstrated by Colombel et al. ${ }^{75}$, who found that only $27 \%$ of patients had documented low TPMT activity. Other confounding genetic and environmental factors include, for instance, the patient's age, renal function, AZA formulation, coadministration of mesalazine (a reversible TPMT inhibitor) and allopurinol (XO inhibitor). Thus, the determination of TPMT activity is not an exclusive test to rely on. It may be helpful only in identifying a certain group of high-risk patients but, as the negative predictive value is rather low, it is not beneficial in ruling out possible side-effects. Also, as the prevalence of double carriage of variant TPMT alleles is as low as $1 / 300$, continuous monitoring of red blood cell counts remains mandatory in clinical practice.

The clinical usefulness of arylamine-N-acetyltransferase 1 (NAT1), glucocorticoid receptor (GCR), MDR1 gene, DLG5, TNF, Fas-ligand, NOD2/CARD15, or $5 \mathrm{q} 31$ in predicting response to 5-aminosalicylate, glucocorticoids or infliximab is even more controversial.

\section{Biomarkers}

\section{Serological markers}

Anti-neutrophil cytoplasmic antibody: The classical anti-neutrophil cytoplasmic antibody (ANCA) tests are used to diagnose and monitor the inflammatory activity in primary small vessel vasculitides. On the basis of an international consensus statement, ANCA testing is performed with serum samples by indirect immunofluorescence (IIF) on normal peripheral blood neutrophils. Atypical p-ANCA are most commonly seen in patients with IBD, especially $\mathrm{UC}$, and some autoimmune liver diseases such as autoimmune hepatitis and primary sclerosing cholangitis.

Atypical p-ANCA is present in the sera of $40-80 \%$ of patients with $\mathrm{UC}^{76,77}$ and to a lesser extent in CD $(5-25 \%)^{78}$. The prevalence of the antibody is also high in patients with primary sclerosing cholangitis $(88 \%)^{79}$ and autoimmune hepatitis type I $(81 \%)^{80}$, but is detected in only $1-3 \%$ of healthy control subjects. Some sera with atypical ANCA reactivity are positive for antibodies to elastase, lactoferrin, cathepsin G, lysozyme or bactericidal permeabilityincreasing protein (BPI). However, since they are detected in only a few atypical p-ANCA-positive sera, these antigens do not appear to be the primary targets of atypical p-ANCA reactivity. The exact target antigen(s) of atypical p-ANCA has not yet been identified.

An alternative method for the identification of atypical p-ANCA reactivity developed by Targan and colleagues uses a three-step process that includes enzyme-linked immunosorbent assay (ELISA) analysis, IIF assay on methanolfixed neutrophils, followed by another IIF testing on deoxyribonuclease (DNase)-treated neutrophils. DNase-sensitive p-ANCA (i.e. not detectable on DNase-treated neutrophils) is present in the sera of $60-80 \%$ of the patients with 
UC and in approximately $10-30 \%$ of CD patients. In approximately $70 \%$ of $\mathrm{UC}$ sera there is ablation of the p-ANCA pattern and antigen recognition after DNase digestion of the substrate cells ${ }^{81}$. This suggests that the epitope recognized by the UC-associated atypical p-ANCA is a protein-DNA complex, or that the presence of intact DNA is necessary for maintaining the integrity of the epitope. In up to $30 \%$ of the sera there is conversion to homogeneous cytoplasmic staining, while in $3 \%$ of the sera the p-ANCA pattern was retained after DNase treatment of the substrate.

The overall specificity of atypical p-ANCA is $84-95 \%$, with a sensitivity of $48-63 \%$, a positive predictive value (PPV) of $69 \%$, and a negative predictive value (NPV) of $89 \%{ }^{8}$.

Anti-Saccharomyces cerevisiae antibodies: The other 'conventional' markers, anti-Saccharomyces cerevisiae antibodies (ASCA) are antibodies directed primarily against a $200 \mathrm{kDa}$ phosphopeptidomannan cell wall component of the common baker's or brewer's yeast $S$. cerevisiae ${ }^{82}$, eliciting the formation of both IgA and IgG antibodies. Separate and polyvalent ELISA configurations are available for ASCA IgG and IgA detection. ASCA are more frequently found in CD patients (50-80\%) compared to patients with UC (2-14\%) and normal healthy subjects $(1-7 \%)^{83-85}$. Approximately two-thirds of CD patients with ASCA IgG are also positive for ASCA IgA, yet $0-19 \%$ of the patients have only ASCA IgA antibodies. This finding suggests that both ASCA IgG and IgA antibodies should be measured. In CD up to $90 \%$ specificity has been reported in specimens positive for both ASCA IgG and $\operatorname{IgA}$ antibodies, especially when the titre of both ASCA antibodies, IgG and IgA, is high ${ }^{86}$. Sensitivity of ASCA testing ranges from $41 \%$ to $76 \%$, with a PPV of $88 \%$ and NPV of $68 \%{ }^{87}$.

ASCA IgG and IgA levels in CD patients are highly variable ${ }^{85,86}$. The prevalence of ASCA is much higher in cases of sporadic CD and in families with only CD (63\%) compared to families with both CD and UC (33\%). The familial trait to ASCA is obvious, but it is questionable whether this is due to the genetic background or the effect of environmental agents during childhood predisposing to the disease.

Newly discovered serological markers: Anti-OmpC antibody is directed against the outer membrane porin $\mathrm{C}$ transport protein of Escherichia coli. The detection of the IgA antibody is done with ELISA. Anti-OmpC has been reported in $30-55 \%$ of CD patients ${ }^{85,88}$, but in children and young adults it was reported in only $24 \%{ }^{89}$. The prevalence of anti-OmpC was insignificant in UC patients and in healthy subjects (5-11\% and 5\%, respectively). Anti-OmpC may be of value to aid diagnosis of ASCA-negative CD patients. The prevalence of anti-OmpC among ASCA-negative patients is 5-15\%.

A fragment of bacterial DNA (I2), a homologue of the tetR bacterial transcriptional factor family, has been identified from lamina propria mononuclear cells in active CD and shown to be associated with Pseudomonas fluorescens $^{90,91}$. IgA anti-I2 antibodies have been detected by ELISA in IBD patients with a seroprevalence of $54 \%$ in CD and $10 \%$ in UC. Anti-I2 antibodies were also found in patients with other inflammatory enteritis (19\%) as well as in healthy subjects $(4 \%)^{78}$. 
Serological expression cloning was used by Lodes et al. to identify commensal bacterial proteins in colitic mice. The dominant antigens were found to be flagellins. Intense $\mathrm{B}$-cell and $\mathrm{CD} 4^{+} \mathrm{T}$-cell responses were observed against one of these flagellins (anti-CBir1). Colitis was induced when the T-cell line specific for CBirl was transferred into naive severe combined immunodeficient mice. Approximately $50 \%$ of patients with $\mathrm{CD}$ have IgG serum reactivity to CBirl versus $6 \%$ of $\mathrm{UC}$ patients and $8 \%$ of healthy subjects. CBir 1 is the first bacterial antigen to induce colitis in animal IBD models and also leads to a pathological immune response in IBD patients ${ }^{92}$. Among the population of CD patients positive for atypical p-ANCA, but who do not react to other known antigens, $40-44 \%$ are positive for anti-CBir1, in contrast to UC patients who are positive for atypical p-ANCA. In this latter group it has been found in only $4 \%$ of individuals. Serum responses to CBir 1 may be of help in differentiating between atypical p-ANCA-positive CD and UC patients, independently of ASCA ${ }^{93}$.

Anti-pancreatic antibodies (PAB) are directed against the exocrine pancreatic tissue. The exact target antigen(s), however, have not yet been identified. These antibodies are detected using IIF on human pancreas substrate. The reported prevalence of PAB is approximately $30 \%$ in CD patients compared to $2-6 \%$ of UC patients and $0-2 \%$ of control subjects ${ }^{94}$. The relevance of $\mathrm{PAB}$ in the pathogenesis of $\mathrm{CD}$ is unclear, and whether the presence of PAB identifies a CD subgroup also remains to be determined ${ }^{95}$.

Patients with $\mathrm{CD}$ express antibodies to cell wall carbohydrate epitopes present in different pathogenic bacteria and fungi. Using a glycan array (GlycoChip) and ELISA, antiglycan antibodies have been detected in CD patients, including anti-laminaribioside carbohydrate antibody (ALCA) (18$38 \%$ ), anti-chitobioside carbohydrate antibody (ACCA, 21-36\%), and antimannobioside carbohydrate antibody (AMCA, 28\%) ${ }^{96,97}$. Importantly, 24 $44 \%$ of ASCA-negative CD patients, in one study, were found to be positive for one or more of the antiglycan antibodies. Patients with $\mathrm{CD}$ who were positive for at least one of ALCA, ACCA, or gASCA (very similar to conventional ASCA) could be differentiated from UC patients, with $77 \%$ sensitivity and more than $90 \%$ specificity. The PPV and NPV were $91 \%$ and $77 \%$, respectively. When the same criteria were applied to differentiate CD from control patients, the specificity fell to $70.3 \%$. As one might expect, combining two or more antiglycan antibodies resulted in a higher specificity and PPV in differentiating CD from UC, but with a loss of sensitivity, NPV, and efficiency.

The prevalence of different serological markers in IBD and their association with the disease phenotype is summarized in Table 2.

\section{DIAGNOSTIC VALUE OF SEROLOGICAL MARKERS IN IBD}

The role of atypical p-ANCA and ASCA as diagnostic markers for IBD appears to be limited because of their moderate sensitivity and presence in other conditions. Atypical p-ANCA can also be observed in other forms of colitis; for instance collagenous or eosinophilic colitis, and in various autoimmune liver diseases such as autoimmune hepatitis (AIH) and primary 
PATHOGENESIS AND CLINICAL PRACTICE IN GASTROENTEROLOGY

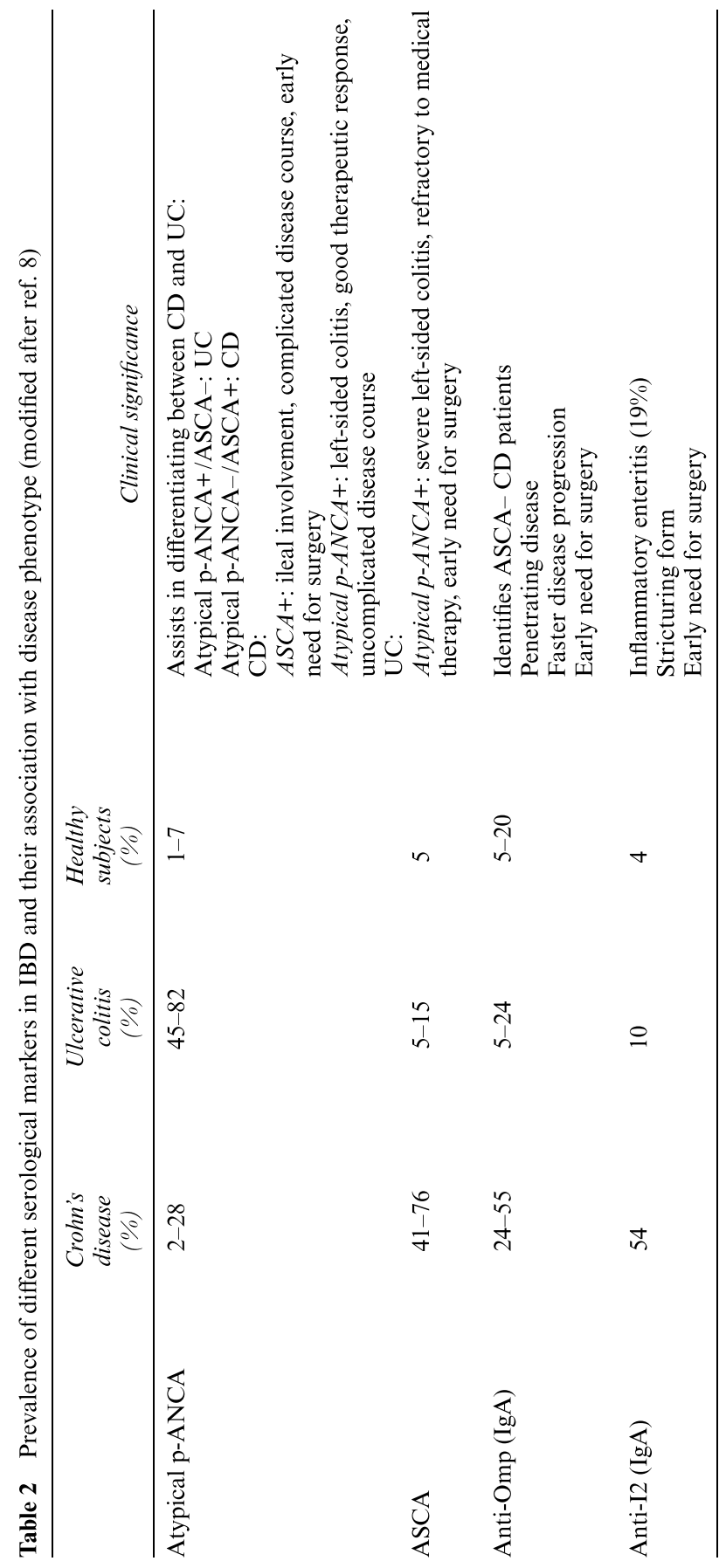


GENETICS, IMMUNOLOGY AND BIOMARKERS IN CLINICAL PRACTICE

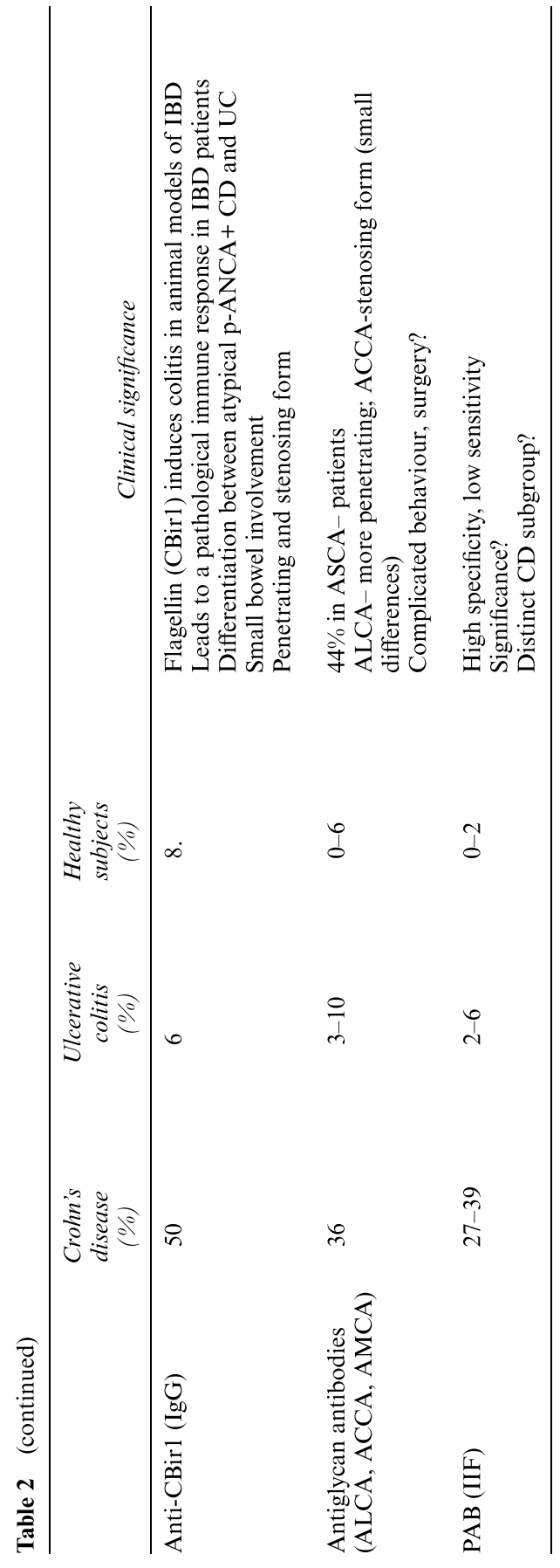


sclerosing cholangitis (PSC) ${ }^{98,99}$. ASCA has been found in autoimmune hepatitis $(20 \%)$ and gastrointestinal disorders such as coeliac disease ${ }^{100}$.

The combination of atypical p-ANCA and ASCA, however, may be of help in patients in whom distinction between $C D$ and UC is not obvious with the classic diagnostic tools (patient history, radiological examination, endoscopy, and biopsy). The ASCA+/atypical p-ANCA- serological pattern is mainly characteristic of $\mathrm{CD}$, while the ASCA-/atypical p-ANCA+ is characteristic of UC. Several independent studies found that these combinations had sensitivities ranging from $30 \%$ to $64 \%$, specificity of more than $90 \%$, and a PPV from $77 \%$ to $96 \%^{84,85,101,102}$. It must be emphasized that neither ASCA nor atypical p-ANCA negativity rules out IBD. Similarly, the presence of these antibodies does not confirm the diagnosis of IBD.

Several groups have studied whether atypical p-ANCA and ASCA are subclinical markers of familial IBD. Some studies ${ }^{103,104}$ showed that atypical p-ANCA occurred frequently in healthy first-degree relatives of UC patients, whereas other studies were unable to confirm this observation ${ }^{105,106}$. ASCA positivity was obviously found at a higher rate in unaffected first-degree relatives of CD patients than in the general population $(20-25 \% \mathrm{vs} 5 \%)^{107,108}$. Further studies are necessary to clarify whether the unaffected, ASCA-positive, family members face an increased risk of disease development.

In addition, Israeli et al. ${ }^{109}$ demonstrated that the presence of ASCA and atypical p-ANCA in healthy subjects can predict for the occurrence of IBD before the emergence of overt clinical manifestations. Serum samples were systematically obtained and stored from $5 \%$ of all military recruits. ASCA were detected in $31 \%$ of $\mathrm{CD}$ patients before clinical diagnosis. The mean interval between ASCA detection and diagnosis was 38 months. There was no ASCA positivity in the control population. Atypical p-ANCA was present in $25 \%$ of patients with available sera before the diagnosis of UC. None of their 24 matched controls was positive.

At last, serological evaluation may be of help in patients with indeterminate colitis (IC) to increase the diagnostic accuracy. Ninety-seven patients with IC were enrolled, analysed for atypical p-ANCA and ASCA, and followed up prospectively in a multicentre study by Joossens et al. At the end of the 1-year follow-up a definitive diagnosis was reached in 31 of 97 patients $(37 \%)$. In IC patients, ASCA+/atypical p-ANCA - results correlated with CD in $80 \%$, whereas ASCA-/atypical p-ANCA+ correlated with UC in $63 \%$. The remaining ASCA-/atypical ANCA+ patients were eventually determined to suffer from CD, but clinically showed a UC-like CD phenotype. Remarkably, during the 9.9 years of follow-up, $48.5 \%$ of the patients did not demonstrate ASCA or atypical p-ANCA. In $85 \%$ of these seronegative patients the diagnosis remained indeterminate. In contrast, $48 \%$ of the seropositive patients were declared to have $\mathrm{CD}$ or $\mathrm{UC}$ on follow-up ${ }^{110}$. Adding anti-OmpC and anti-I 2 to the serological panel in patients with IC did not add diagnostic clarification ${ }^{111}$.

Recently, a sophisticated, computer-aided system was developed from a sequential analysis of serological assay results using two-stage statistical classifiers including a neural network. In the validation cohort the overall accuracy of the panel for IBD diagnosis was as high as $92 \%$ (sensitivity $93 \%$, specificity $95 \%)^{112}$. 


\section{ASSOCIATION WITH DISEASE PHENOTYPES AND PROGRESSION}

The occurrence of atypical p-ANCA in UC is associated with a characteristic clinical appearance and represents a distinct subgroup that is often characterized by specific HLA markers. These patients have a higher probability to develop a severe left-sided UC, which is more resistant to treatment than the usual case. The disease has a more aggressive pattern requiring surgery earlier in the course of the disease ${ }^{113}$. Some authors suggest that pouchitis develops more frequently after ileal pouch anastomosis ${ }^{114}$, whereas others were unable to confirm this observation. The presence of atypical p-ANCA identifies a subgroup of CD patients characterized by 'UClike' colitis; the inflammation usually involves the left side of the colon and the response to therapy is generally good. The atypical p-ANCA in CD patients is associated with a later age of onset and a relatively lower incidence of complications, such as strictures and/or perforations ${ }^{115-117}$.

The phenotype and the disease course of CD depend heavily on the presence and extent of the serological response targeted against various microbial antigens. In patients with an ASCA+ (IgG and/or IgA)/atypical p-ANCAphenotype, small bowel involvement (with or without colonic disease) is more typical than the pure colonic disease $(68-76 \% \text { vs } 34-46 \%)^{84,85,118,119}$. ASCA positivity predicts a more aggressive disease course with a higher rate of complications. ASCA have been associated with stricturing (70\%) and penetrating $(51 \%)$ forms of disease as opposed to the inflammatory one $(14 \%)$ and a higher risk of small bowel resection ${ }^{113,116,120}$. Several studies suggest that ASCA positivity is associated with an earlier onset of disease ${ }^{115}$. ASCA IgA positivity in children may represent a higher risk for relapses (OR 2.9, 95\% CI $1.33-6.33)^{121}$.

The presence of anti-OmpC in adult $\mathrm{CD}$ patients is associated with increased prevalence of the penetrating form only ${ }^{87,116,117}$, while in children both the penetrating and stenosing forms ${ }^{122}$ are more frequent. Moreover, antibody positivity may lead to a more aggressive course of disease and a higher risk for surgical interventions.

Like ASCA and anti-OmpC, anti-I2 also appears to be associated with an increased risk for complications in adult $\mathrm{CD}$ patients. It is an independent risk factor for the development of the stenosing form and the need for surgical interventions $85,87,116,117$.

Recent research has shown that the anti-CBir1 antibody is associated with ileal involvement in adult $\mathrm{CD}$ patients independent of other serological markers, and it predisposes to the development of both stenosing and penetrating forms ${ }^{92}$.

Among the antiglycan antibodies in CD, ALCA is more often positive in the penetrating form (34\% vs $25 \%)$ and ACCA in the stenosing one $(29 \%$ vs $18 \%)$ when compared to the inflammatory type. Nonetheless, the differences are small. No correlation was found between antiglycan positivity and the need for small bowel resections.

The number of antibodies produced against microbial antigens in CD shows a positive correlation with the severity of the disease. Mow et al. ${ }^{120}$ retrospectively analysed 303 patients and found that the simultaneous 
presence of three antibodies (ASCA, anti-OmpC, and anti-I2) resulted in an increased risk of complications (stenosing form $72 \%$ vs $23 \%$, penetrating form $58.7 \%$ vs $27.9 \%$, and the need for surgical intervention $72 \%$ vs $23 \%$, as compared to the seronegative group. When all three antibodies were present, the OR was 8.6 (95\% CI 4.0-18.9).

In addition to qualitative correlations, quantitative correlations with serological responses are also present. Patients expressing high titres of serological markers are more likely to have a complicated course of small bowel CD. In a prospective paediatric cohort $(n=196)$, Dubinsky et al. ${ }^{122}$ found, as did Mow et al. ${ }^{120}$, that the presence and magnitude of immune responses to microbial antigens (ASCA, anti-OmpC, anti-I2, and anti-CBir1) are significantly associated with more aggressive disease phenotype. The risk of developing penetrating and/or stricturing CD was increased 11-fold in those individuals with immune responses to all four microbial antigens compared to seronegative cases (95\% CI 1.5-80.4). Moreover, they demonstrated that the duration required to develop a disease complication during the 18 months of follow-up period was significantly shorter in those children who had a serological response against at least one antigen. A difference exists between cohort studies performed in children and adults, indicating variations with regard to which immune response has the greatest effect on disease course in children and adults. The explanation for this variability is not yet known.

The presence and elevated titre of several antiglycan antibodies also predisposes to the development of complicated ileal $\mathrm{CD}^{97}$. In patients positive for more than two antiglycan antibodies (ALCA, ACCA, gASCA), ileal involvement can be seen in $93 \%$ of the cases, as compared to seronegative patients (60\%) (OR 9.0, 95\% CI 3.3-24.5). High ALCA titres seem to correlate with small bowel involvement and the development of stenosing and penetrating disease forms. ACCA titres, on the other hand, demonstrated no such associations.

One should be aware of the fact that blatantly striking differences in serological response are demonstrated only in a minority of patients. About one in four of the patients are positive for several antibodies and have markedly, and simultaneously, elevated antibody titres. The proportion of seronegative patients, or patients positive for only one antigen with a low antibody titre, is approximately equal. The remaining $50 \%$ of all CD patients have an intermediate phenotype based on the serological assessments. The aim is to find new serological markers which will be utilized to identify certain homogeneous groups of patients in this 'grey zone' of disease progression and response to therapy.

\section{SEROLOGICAL MARKERS IN THE FOLLOW-UP AND TREATMENT OF IBD}

In patients with UC no correlation was found between the presence and titre of atypical p-ANCA and the activity of the disease. The titre of atypical p-ANCA remains unchanged even after a colectomy ${ }^{123}$. Similarly, the presence of ASCA in CD patients is relatively constant during the course of the disease and seems to be independent of disease activity ${ }^{15,118}$. As a consequence, neither atypical 
p-ANCA nor ASCA is suitable for monitoring of the disease. The ALCA and ACCA titres also seem to be independent of disease activity, but rather depend on disease duration ${ }^{97}$. The prevalence of ASCA, anti-I2, anti-OmpC, and the presence of multiple serological responses are more frequent when the disease persists for a long period of time ${ }^{116,124}$

Landers et al. discovered that, following anti-TNF- $\alpha$ treatment, the prevalence and titre of various antibodies (ASCA, atypical p-ANCA, anti-I2, and anti-OmpC) remained unchanged in the majority of patients ${ }^{88}$. Mesalamine treatment also leaves the ASCA level unchanged in active CD patients $^{125}$. ASCA positivity remains even after steroid treatment, yet the antibody titre declines ${ }^{126}$.

The role of the serological response in the prediction of therapeutic effectiveness is yet to be determined. A Belgian study involving $279 \mathrm{CD}$ patients failed to find any correlation between the atypical p-ANCA or ASCA positivity and the rate of response of patients given anti-TNF- $\alpha$ treatment. The investigators observed a generally poorer responsiveness in the case of atypical p-ANCA+/ASCA - status, but the difference was insignificant ${ }^{127}$.

Patients exhibiting serological responses directed against various microbial antigens (OmpC and $\mathrm{I} 2$ ) should expect a higher remission rate if the budesonide treatment was supplemented with ciprofloxacin and metronidazole, while in the anti-OmpC/I2 seronegative group budesonide treatment alone proved to be more effective ${ }^{128}$. The study raises the possibility that certain antibiotics are more effective in those CD patients who present with a marked immunological response against microbial antigens. This group of patients may be the one that can be most effectively treated through manipulation of the bacterial flora.

\section{SEROLOGICAL MARKERS AND RECEPTORS PARTICIPATING IN INNATE IMMUNITY}

Genetic heterogeneity may be responsible for the differences found in the serological response. Literature references are divided regarding the possible correlation between antibody production in patients with CD and the NOD2/ CARD15 status. Several studies found serological response (atypical p-ANCA, anti-I2, anti-OmpC, ASCA IgG/A) to be independent of the NOD2/CARD15 status ${ }^{117,120}$. Belgian and Hungarian work groups, on the other hand, confirmed the proposed association in large $(n=913$ and $n=658$, respectively) cohorts of patients. When more than one NOD2/CARD15 mutation was present, the investigators found the rate of ASCA, gASCA positivity and their titres to be significantly higher. Moreover, they found a positive correlation between the number of mutations and the prevalence of ASCA, gASCA, and ALCA, which may indicate a gene dose effect ${ }^{85,97}$.

Investigating the association of the serological response with the toll-like receptor (TLR)-4 gene D299G (Asp299Gly) polymorphism led to results contrasting those found with the NOD2/CARD15 assessments. If the patient had a variant TLR4 genotype the rates of ACCA and Omp positivity were less frequent compared to the wild type, which again suggests a gene dose effect. 
Polymorphisms may also play a role in the development of serological responses against the Gram-negative E. coli membrane protein. The Belgian work group also found a correlation between anti-Omp positivity and TLR4 gene polymorphism in patients with ulcerative colitis $(n=272)^{127}$. Anti-Omp positivity was significantly lower among patients with a TLR4 variant genotype and prevalence of the antibody showed an inverse correlation with the number of variants. This was, however, not confirmed by findings of the Hungarian group for either ASCA or Omp.

\section{SERUM AND FECAL MARKERS}

\section{C-reactive protein (CRP), erythrocyte sedimentation rate (ESR) and other laboratory markers}

ESR and CRP are traditional non-specific markers for inflammation. ESR is defined as the rate at which erythrocytes migrate through the plasma. Inevitably, ESR will depend on the plasma concentration and on the number and size of the erythrocytes. Conditions such as anaemia, polycythemia, and thalassaemia affect ESR. Compared with CRP, ESR will peak much less rapidly and may also take several days to decrease, even if the clinical condition of the patient or the inflammation is ameliorated. Increases in ESR with age have also been described ${ }^{129}$.

CRP is a pentameric protein consisting of five monomers and is one of the most important acute-phase proteins in humans ${ }^{130}$. Under normal circumstances CRP is produced by hepatocytes in low quantities $(<1 \mathrm{mg} / \mathrm{L})$. However, following an acute-phase stimulus, such as inflammation, hepatocytes rapidly increase the production of CRP and may reach peak levels of $350-400 \mathrm{mg} / \mathrm{L}$. Generally, CRP levels of $10-40 \mathrm{mg} / \mathrm{L}$ are found in cases of mild inflammation or viral infections ${ }^{131,132}$.

Although CRP is non-specifically up-regulated in most inflammatory diseases, including IBD, there is remarkable heterogeneity in the CRP response between $\mathrm{CD}$ and $\mathrm{UC}$. Whereas $\mathrm{CD}$ is associated with a strong CRP response, UC has only a modest or no CRP response in both adult and paediatric IBD populations ${ }^{133,134}$. This is an important fact to keep in mind when using CRP in clinical practice. There is no good explanation for this heterogeneity. Recent studies have suggested that polymorphisms in the CRP gene, located on the long arm of chromosome 1 (1q23-24), account for interindividual differences in baseline CRP production in humans. Results are, however, conflicting, and one recent study investigating CRP polymorphisms in IBD patients showed no clear association with serum CRP levels ${ }^{135}$.

More generally used laboratory markers include white blood cell count, platelets, and albumin. The white blood cell count will increase as part of the acute-phase response. Increased leukocytosis is therefore not a specific feature of IBD and may also be seen in other inflammatory conditions and stressful events. White blood cell count is also influenced by some treatments used in IBD, such as glucocorticoids (increased) or azathioprine and 6-mercaptopurine 
(decreased). Platelet count will also increase and is therefore an indication, without being a specific marker, of inflammation. Albumin is a typical example of a negative acute-phase reactant and decreased levels may be found during inflammation. However, other conditions such as malnutrition and malabsorption may also lead to low albumin levels. Other acute-phase reactants include sialic acid, $\alpha_{1}$-acid glycoprotein or orosomucoid, fibrinogen, lactoferrin, $\beta_{2}$-microglobulin, serum amyloid $A, \alpha_{2}$-globulin, and $\alpha_{1}$ antitrypsin, but these have not been widely studied in IBD.

A number of potentially important new serum markers could be identified by using advanced technology. Recently, protein sera profiles of 30-30 CD, UC, inflammatory and healthy controls were obtained with a surface enhanced laser desorption ionization-time of flight-mass spectrometer (SELDI-TOF-MS). This technology and the use of the multiple decision trees method led to protein biomarker patterns analysis and allowed for the selection of potential individual biomarkers with good sensitivity and specificity (minimum 80\%). Four biomarkers showed important diagnostic value (PF4, MRP8, FIBA, and $\mathrm{Hpa} 2)^{136}$.

\section{Faecal calprotectin and other faecal markers}

A number of neutrophil-derived proteins present in stool have been studied, including faecal lactoferrin, lysozyme, elastase, myeloperoxidase, and calprotectin $^{137,138}$. Calprotectin, a $36 \mathrm{kDa}$ calcium- and zinc-binding protein, is probably the most promising marker for various reasons. In contrast with other neutrophil markers, calprotectin represents $60 \%$ of cytosolic proteins in granulocytes. The presence of calprotectin in faeces can therefore be seen as directly proportional to neutrophil migration to the gastrointestinal tract. Although calprotectin is a very sensitive marker for detecting inflammation in the gastrointestinal tract, it is not a specific marker and increased levels are also found in neoplasia, IBD, infections, and polyps. Faecal calprotectin is a very stable marker (stable for more than 1 week at room temperature) and is resistant to degradation, which makes it an attractive option. Early studies using faecal calprotectin in IBD have shown a good correlation with In-labelled leukocyte excretion and intestinal permeability ${ }^{139}$. Interestingly, increased faecal calprotectin levels have been reported after the use of non-steroidal anti-inflammatory drugs as well as with increasing age.

Further, potentially interesting markers are faecal S100A12 (calgranulin C) ${ }^{140}$ and lactoferrin ${ }^{141}$. Calgranulin $\mathrm{C}$ is a member of the S100 family of calcium-binding proteins specifically expressed by granulocytes. Extracellular S100A12 exhibits proinflammatory functions, including potent chemotactic activity, comparable with other chemotactic agents. In addition, bovine S100A12 is a ligand for the receptor for advanced glycation end-products (RAGE), which is found on macrophages, endothelium, and lymphocytes. Binding of S100A12 to RAGE mediates its proinflammatory properties. 


\section{Diagnostic value of biomarkers in IBD}

Only a few studies have investigated the value of laboratory markers in identifying individuals at risk for IBD. An early study from Shine et al. investigated 82 adults referred with abdominal symptoms ${ }^{142}$. In all patients a clinical examination, as well as a rectal biopsy, were performed, and ESR and CRP were determined. Of these markers, CRP was increased in all patients who subsequently were diagnosed with CD $(n=19)$, in $50 \%$ of patients diagnosed with UC $(n=22)$, yet in none of the 41 patients with functional bowel symptoms. In a paediatric study by Beattie et al., children underwent extensive blood analysis (including haemoglobin, leukocyte count, platelet count, ESR, albumin, and CRP), ileocolonoscopy, and small bowel followthrough $^{133}$. Twenty-six children were finally diagnosed with CD, 13 with UC, eight with polyps, seven with various gastrointestinal disorders and 37 had a normal investigation. The best laboratory marker in differentiating IBD from controls was CRP. Similar to the study by Shine and colleagues, $100 \%$ of CD patients but only $60 \%$ of UC patients had increased CRP compared with none of the children with polyps or those with a normal investigation. ESR proved to be the second-best marker. Finally, a more recent, larger study in 203 individuals referred for symptoms suggestive of lower bowel disease also showed that CRP was a good marker in differentiating IBD from irritable bowel syndrome (IBS) ${ }^{143}$. Together, these studies seem to suggest that CRP is the most sensitive marker in detecting IBD, but values range between $50 \%$ and $60 \%$ for UC and between $70 \%$ and $100 \%$ for CD, and also depend on the cut-off value used. In addition, high-sensitivity CRP assays have been studied in other inflammatory conditions, such as atherosclerotic heart disease.

Faecal calprotectin has been shown to enable the diagnosis of IBD. In this respect a cut-off value of $30 \mu \mathrm{g} / \mathrm{g}$ had $100 \%$ sensitivity in discriminating active CD from IBS in the study by Tibble and colleagues ${ }^{137}$. In a paediatric study by Fagerberg and colleagues ${ }^{144}, 36$ children with symptoms and suspected inflammation of the colon were subjected to stool analysis for faecal calprotectin and an ileocolonoscopy. Twenty-two patients showed inflammation on endoscopy (of whom 20 were later diagnosed with IBD), and calprotectin levels were much higher in these patients than in children without inflammation on endoscopy. The authors concluded that faecal calprotectin is helpful in the detection of colonic inflammation in children with gastrointestinal symptoms suggestive of IBD, and that a positive test may prioritize endoscopy. Interestingly, similarly to serological markers, increased faecal calprotectin has been described in healthy first-degree relatives of patients with $\mathrm{CD}^{145}$. In a recent meta-analysis by von Roon et al. ${ }^{146}$ the authors concluded that calprotectin possessed a good diagnostic value in distinguishing IBD from non-IBD diagnoses; however, at a cut-off value of $100 \mu \mathrm{g} / \mathrm{g}$. 


\section{DO BIOMARKERS PREDICT DISEASE ACTIVITY, COURSE, AND EFFICACY OF TREATMENT IN IBD?}

IBD follows an alternating disease course and both CD and UC are characterized by periods of remission and relapses. However, disease flare-ups occur in a random way and are often unpredictable.

CRP has been shown to be a good marker for predicting disease course and outcome in a number of diseases, thus its alteration is non-specific for IBD. Its most well-known association is with cardiovascular disease and poor outcome after myocardial infarction ${ }^{147}$, and a poor prognosis in multiple myeloma ${ }^{148}$.

In general, patients with severe disease more often have abnormal inflammatory markers, compared with patients without or with only lowgrade inflammation. This has been shown in a prospective study by Tromm and colleagues $^{149}$, who investigated laboratory markers, including ESR, serum albumin, $\alpha_{1}$-proteinase inhibitor, cholinesterase, CRP, and haematocrit, and correlated them with endoscopic activity. One of the early studies in IBD showed a good correlation between ESR and clinical activity ${ }^{150}$. The correlation was, however, dependent on disease location, and ESR did not correlate as well with UC restricted to the rectum and with CD restricted to the upper small bowel. The study by Fagan et al. showed that both CRP and ESR correlated well with disease activity but the correlation was better for CRP ${ }^{151}$. In addition, the correlation of laboratory markers with disease activity has been shown to be much stronger for CD than for UC. However, a wide range of CRP values was observed and no clear cut-off values exist between mild to moderate $(10-50 \mathrm{mg} / \mathrm{L})$, moderate to severe $(50-80 \mathrm{mg} / \mathrm{L})$, and severe disease (>80 mg/L). Therefore, the comparison of individual CRP values with previous values in any given patient is of great clinical importance. Lastly, CRP showed acceptable correlation with endoscopic and histological activity in $\mathrm{CD}^{152}$. For UC, again, this correlation was weaker. In contrast, recent data from Australia suggested that a subgroup of patients with active ileal disease, low body mass index (BMI), and previous ileocaecal resection was characterized by low CRP $\mathrm{P}^{153}$.

In $\mathrm{CD}$ a number of studies have investigated a panel of laboratory markers in predicting clinical relapse. In a prospective study by Brignola et al. $41 \mathrm{CD}$ patients with clinically inactive disease (CD activity index $<150$ ) were followed-up for 6 months using a panel of inflammatory markers (ESR, white blood cells, haemoglobin, albumin, $\alpha_{2}$-globulin, serum iron, CRP, $\alpha_{1}$ glycoprotein, and $\alpha_{2}$-antitrypsin) ${ }^{154}$. A total of $17 / 41$ patients relapsed. ESR, $\alpha_{2}$-globulin, and $\alpha_{1}$-glycoprotein proved best at distinguishing relapsers from non-relapsers. Based on these markers a prognostic index (PI) was calculated. Using this threshold all patients with a PI $>0.35$ relapsed over a period of 18 months, compared with $5 / 29$ patients with a PI $<0.35$. Later, Boirivant et al. prospectively followed 101 outpatients with $\mathrm{CD}^{155}$. Half of the patients had an elevated CRP value and this correlated well with clinical activity. Approximately one-third of CD patients presented with active disease despite normal CRP and one-third had high CRP levels but clinically inactive disease. The likelihood of relapse after 2 years was higher in the patients with an increased CRP compared with those who had normal CRP. 
More recently, the GETAID group ${ }^{156}$ proposed a simple biological score for predicting short-term relapse in CD. Multivariate analysis selected two markers predictive of relapse: CRP $>20 \mathrm{mg} / \mathrm{L}$ and an ESR $>15 \mathrm{~mm} / \mathrm{h}$. The relative risk of short-term relapse for patients with a positive score compared to those with a negative score was 8.0 (95\% CI 2.8-22.9). Sensitivity of the score was $89 \%$ and specificity was $43 \%$ with a negative predictive value of $97 \%$, suggesting that normal CRP and ESR could almost certainly rule out a relapse in the next 6 weeks.

Much less data exist on the value of laboratory markers in assessing disease course and outcome in UC. The well-known prospective study from Oxford evaluated 49 severe UC patients treated with hydrocortisone and/or cyclosporin $(n=49)$. On day 3 a daily stool frequency of $>8$ or $3-8$ with increased CRP ( $>45 \mathrm{mg} / \mathrm{L}$ ) predicted with $85 \%$ certainty the need for colectomy ${ }^{157}$. Only one relatively small study investigated the role of hs-CRP in IBD $^{158}$. Ninety CD, 70 UC patients, and 160 controls were investigated. The coefficient of correlation between hs-CRP and the disease activity score was weak but similar in both UC (0.26) and CD (0.36).

More recently, faecal calprotectin was shown to predict relapse of $\mathrm{CD}$. In a study by Tibble et al. calprotectin levels of $50 \mu \mathrm{g} / \mathrm{g}$ or more predicted a 13 -fold increased risk for relapse ${ }^{159}$. In another study ${ }^{160}, 38 \mathrm{CD}$ and $41 \mathrm{UC}$ patients were investigated. All patients were in remission for a mean duration of 5 months. A baseline level of calprotectin of $150 \mu \mathrm{g} / \mathrm{g}$ or more was predictive for a relapse in the next year. Although sensitivity was high for both CD $(87 \%)$ and UC $(89 \%)$, specificity was much lower in the case of CD $(43 \%)$ compared to UC $(82 \%)$. Similarly, in a recent study, faecal calprotectin and lactoferrin were able to differentiate organic colorectal disease and were associated with active disease at endoscopy, both in UC (78\% and 75\%, respectively) and in CD ( $87 \%$ and $82 \%$, respectively $)^{161}$; however, specificity was overall low. It is thus difficult to conclude from cut-off values based on these studies.

In addition to serum markers, faecal calprotectin also correlates well with endoscopic and histological activity in patients with UC and CD, and elevated calprotectin levels normalize once the inflammation has resolved ${ }^{162}$. The role of further possible markers (e.g. $\beta_{2}$-microglobulin) is conflicting.

A change in CRP, following therapy, serves as a good parameter in assessing the effectiveness of the drug on the underlying inflammation. A decrease in $\mathrm{CRP}$, in response to therapy, is objective evidence that the drug has a beneficial effect on intestinal inflammation, even in patients with small changes in their symptoms. On the other hand, persistently raised CRP indicates failure of the therapy to control mucosal inflammation. This was clearly demonstrated by the different response rates to anti-TNF- $\alpha$ antibodies in patients with CD.

A high baseline $(5-10 \mathrm{mg} / \mathrm{L})$ CRP value before the start of therapy was associated with a higher response compared to patients with lower CRP ${ }^{163,164}$. These findings raise the question of whether CRP should be included in patient selection for future clinical trials, at least for selected drugs. Furthermore, high CRP ( $>20 \mathrm{mg} / \mathrm{L}$ ) was found to be an independent predictor for relapse after azathioprine withdrawal in patients on azathioprine therapy for longer than 42 months ${ }^{165}$. Lastly, calprotectin, at a cut-off value of $200 \mathrm{mg} / \mathrm{L}$, at 3 months post-surgery, was useful in predicting endoscopic post-surgical recurrence in 
asymptomatic patients with a sensitivity of $63 \%$ and a specificity of $75 \%{ }^{166}$. In contrast, in a recent Italian study ${ }^{167}$, only lactoferrin correlated significantly with CRP and showed a reliable threshold value for systemic inflammation following ileocolonic resection.

\section{CONCLUSIONS}

In conclusion, the answer to the question of whether genetic, immunological or biomarkers are useful in the current everyday clinical practice, is: maybe. Some of the markers (e.g. CRP, ESR, p-ANCA or ASCA) are already widely or increasingly used, while accepting their limitations. Further prospective clinical studies are needed to establish the clinical role for other (e.g. genetic or additional serological) tests in IBD. In the future, specific diagnostic and prognostic panels that include various genetic, serological and other biomarkers, as well as clinical and environmental factors (e.g. smoking) could be the most likely approaches to diagnosis, prediction of disease course, and response to therapy in IBD; however, we have to note that adding genetic aspects will not replace proper clinical judgement by the physician, who relies on the patient's symptoms and clinical phenotype. Finally, recent advances in understanding the immunological events of IBD have led to the discovery of novel biological therapies directed against several key players involved in the inflammatory cascade.

\section{References}

1. Farrokhyar F, Swarbrick ET, Irvine EJ. A critical review of epidemiological studies in inflammatory bowel disease. Scand J Gastroenterol. 2001;36:2-15.

2. Lakatos L, Mester G, Erdelyi $\mathrm{Z}$ et al. Striking elevation in the incidence and prevalence of inflammatory bowel disease in a province of Western Hungary between 1977-2001. World J Gastroenterol. 2004;10:404-9.

3. Lakatos L, Lakatos PL. Is the incidence and prevalence of inflammatory bowel diseases increasing in Eastern Europe? Postgrad Med J. 2006;82:332-7.

4. Hugot JP. Inflammatory bowel disease: causes and consequences. Best Pract Res Clin Gastroenterol. 2004;18:447-9.

5. Lakatos PL, Fischer S, Lakatos L, Gal I, Papp J. Current concept on the pathogenesis of IBD: crosstalk between genetic and microbial factors. Pathogenic bacteria, altered bacterial sensing or changes in mucosal integrity take toll? World J Gastroenterol. 2006;12:1829-40.

6. Lakatos L, Pandur T, David G et al. Association of extraintestinal manifestations of inflammatory bowel disease (IBD) in a province of Western Hungary with disease phenotype: results of a 25-year follow-up study. World J Gastroenterol. 2003;9:2300-7.

7. Vermeire S. Review article: Genetic susceptibility and application of genetic testing in clinical management of inflammatory bowel disease. Aliment Pharmacol Ther. 2006;24 (Suppl. 3):2-10

8. Papp M, Norman GL, Altorjay I, Lakatos PL. Utility of serological markers in inflammatory bowel diseases: Gadget or magic? World J Gastroenterol. 2007;13:2028-36.

9. Ogura $\mathrm{Y}$, Bonen DK, Inohara $\mathrm{N}$ et al. A frameshift mutation in NOD2 associated with susceptibility to Crohn's disease. Nature. 2001:411:603-6.

10. Hampe J, Cuthbert A, Croucher PJ et al. Association between insertion mutation in NOD2 gene and Crohn's disease in German and British populations. Lancet. 2001;357:1925-8.

11. Chamaillard M, Girardin SE, Viala J, Philpott DJ. Nods, Nalps, Naip: intracellular regulators of bacterial-induced inflammation. Cell Microbiol. 2003;5:581-92. 


\section{PATHOGENESIS AND CLINICAL PRACTICE IN GASTROENTEROLOGY}

12. Girardin SE, Boneca IG, Viala $\mathbf{J}$ et al. Nod2 is a general sensor of peptidoglycan through muramyl dipeptide (MDP) detection. J Biol Chem. 2003;278:8869-72.

13. Kobayashi KS, Chamaillard M, Ogura $\mathrm{Y}$ et al. Nod2-dependent regulation of innate and adaptive immunity in the intestinal tract. Science. 2005;307:731-4.

14. Linde K, Boor PP, Houwing-Duistermaat JJ, Kuipers EJ, Wilson JH, de Rooij FW. CARD15 and Crohn's disease: healthy homozygous carriers of the $3020 \mathrm{insC}$ frameshift mutation. Am J Gastroenterol. 2003;98:613-17.

15. Abreu MT, Taylor KD, Lin YC et al. Mutations in NOD2 are associated with fibrostenosing disease in patients with Crohn's disease. Gastroenterology. 2002;123:679-88.

16. Heresbach D, Gicquel-Douabin V, Birebent B et al. NOD2/CARD15 gene polymorphisms in Crohn's disease: a genotype-phenotype analysis. Eur J Gastroenterol Hepatol. 2004; 16:55-62.

17. Lesage S, Zouali H, Cezard JP et al. CARD/15/NOD2 mutational analysis and genotypephenotype correlation in 612 patients with inflammatory bowel disease. Am J Hum Genet. 2002;70:845-57.

18. Lakatos PL, Lakatos L, Szalay F et al.; Hungarian IBD Study Group, Mozsik G, Ferenci P. Toll-like receptor 4 and NOD2/CARD15 mutations in Hungarian patients with Crohn disease: phenotype-genotype correlations. World J Gastroenterol. 2005;11:1489-95.

19. Guo QS, Xia B, Jiang Y, Qu Y, Li J. NOD2 3020insC frameshift mutation is not associated with inflammatory bowel disease in Chinese patients of Han nationality. World $\mathrm{J}$ Gastroenterol. 2004:10:1069-71.

20. Inoue N, Tamura K, Kinouchi $\mathrm{Y}$ et al. Lack of common NOD2 variants in Japanese patients with Crohn's disease. Gastroenterology. 2002;123:86-91.

21. Medici V, Mascheretti S, Croucher PJ et al. Extreme heterogeneity in CARD15 and DLG5 Crohn disease-associated polymorphisms between German and Norwegian populations. Eur J Hum Genet. 2006;14:459-68.

22. Hugot JP, Zaccaria I, Cavanaugh J et al. for the IBD International Genetics Consortium Prevalence of CARD15/NOD2 mutations in caucasian healthy people. Am J Gastroenterol. 2007;102:1259-67.

23, Ahmad T, Armuzzi A, Bunce $\mathrm{M}$ et al. The molecular classification of the clinical manifestations of Crohn's disease. Gastroenterology. 2002;122:854-66.

24. Brant SR, Picco MF, Achkar JP et al. Defining complex contributions of NOD2/CARD15 gene mutations age at onset and tobacco use on Crohn's disease phenotypes. Inflamm Bowel Dis. 2003;9:281-9.

25. McGovern DP, Hysi P, Ahmad T et al. Association between a complex insertion/deletion polymorphism in NOD1 (CARD4) and susceptibiliy to inflammatory bowel disease. Hum Mol Genet. 2005; 14:1245-50

26. Zouali $\mathrm{H}$, Lesage $\mathrm{S}$, Merlin $\mathrm{F}$ et al. CARD4/NOD1 is not involved in inflammatory bowel disease. Gut. 2003;52:71-4.

27. Franchimont D, Vermeire S, El Housni $\mathrm{H}$ et al. Deficient host-bacteria interactions in inflammatory bowel disease? The toll-like receptor (TLR)-4 Asp299gly polymorphism is associated with Crohn's disease and ulcerative colitis. Gut. 2004;53:987-92.

28. Campieri M, Gionchetti P. Bacteria as the cause of ulcerative colitis Gut. 2001:48:132-5.

29. Boone DL, Ma A. Connecting the dots from Toll-like receptors to innate immune cells and inflammatory bowel disease. J Clin Invest. 2003;111:1284-6.

30. Cario E, Podosky DK. Differential alteration in intestinal epithelial cell expression of Tolllike receptor 3 (TLR3) and TLR4 in inflammatory bowel disease. Infect Immun. 2000;68:7010-17.

31. Okayama N, Fujimura K, Suehiro Y et al. Simple genotype analysis of the Asp299Gly polymorphism of the Toll-like receptor- 4 gene that is associated with lipopolysaccharide hyporesponsiveness. J Clin Lab Anal. 2002;16:56-8.

32. Gazouli M, Mantzaris G, Kotsinas A et al. Association between polymorphisms in the tolllike receptor4 CD14 and CARD15/NOD2 and inflammatory bowel disease in Greek population. World J Gastroenterol. 2005;11:681-5

33. Brand S, Staudinger T, Schnitzler F et al. The role of Toll-like receptor 4 Asp299Gly and Thr399Ile polymorphisms and CARD15/NOD2 mutations in the susceptibility and phenotype of Crohn's disease. Inflamm Bowel Dis. 2005;11:645-52.

34. Oostenbrug LE, Drenth JP, de Jong DJ et al. Association between toll-like receptor4 and inflammatory bowel disease. Inflamm Bowel Dis. 2005;11:567-75. 
35. Pierik M, Joossens S, Van Steen K et al. Toll-like receptor-1 -2 and -6 polymorphisms influence disease extension in inflammatory bowel diseases. Inflamm Bowel Dis. 2006;12:18.

36. Klein $\mathrm{W}$, Tromm A, Griga T et al. A polymorphism in the CD14 gene is associated with Crohn disease. Scand J Gastroenterol. 2002;37:189-91.

37. Obana N, Takahashi S, Kinouchi $\mathrm{Y}$ et al. Ulcerative colitis is associated with promoter polymorphism of lipopolysaccharide receptor gene CD14. Scand J Gastroenterol. 2002;37:699-704.

38. Peters KE, O'Callaghan NJ, Cavanaugh JA. Lack of association of the CD14 promoter polymorphism - 159C/T with Caucasian inflammatory bowel disease. Scand J Gastroenterol. 2005;40:194-7.

39. Yabuuchi H, Tamai I, Nezu JI et al. A novel membrane transporter OCTN1 mediates multispecific bidirectional and $\mathrm{pH}$-dependent transport of organic cations. J Pharmacol Exp Ther. 1999;289:768-73.

40. Rioux JD, Daly MJ, Silverberg MS et al. Genetic variation in the $5 \mathrm{q} 31$ cytokine gene cluster confers susceptibility to Crohn disease. Nat Genet. 2001;29:223-8.

41. Negoro K, McGovern DP, Kinouchi $\mathrm{Y}$ et al. Analysis of the IBD5 locus and potential gene-gene interactions in Crohn's disease. Gut. 2003;52:541-6.

42. Peltekova VD, Wintle RF, Rubin LA et al. Functional variants of OCTN cation transporter genes are associated with Crohn disease. Nat Genet. 2004;36:471-5.

43. Torok HP, Glas J, Tonenchi L et al. Polymorphisms in the DLG5 and OCTN cation transporter genes in Crohn's disease. Gut. 2005;54:1421-7.

44. Tosa M, Negoro K, Kinouchi Y et al. Lack of association between IBD5 and Crohn's disease in Japanese patients demonstrates population-specific differences in inflammatory bowel disease. Scand J Gastroenterol. 2006;41:48-53.

45. Newman B, Gu X, Wintle R et al. A risk haplotype in the solute carrier family $22 \mathrm{~A} 4 / 22 \mathrm{~A} 5$ gene cluster influences phenotypic expression of Crohn's disease. Gastroenterology. 2005;128:260-9.

46. Vermeire S, Pierik M, Hlavaty $\mathrm{T}$ et al. Association of organic cation transporter risk haplotype with perianal penetrating Crohn's disease but not with susceptibility to IBD. Gastroenterology. 2005;129:1845-53.

47. Nakamura H, Sudo T, Tsuiki H et al. Identification of a novel human homolog of the Drosophila dlg P-dlg specifically expressed in the gland tissues and interacting with p55. FEBS Lett. 1998;433:63-7.

48. Stoll M, Corneliussen B, Costello CM et al. Genetic variation in DLG5 is associated with inflammatory bowel disease. Nat Genet. 2004;36:476-80.

49. Daly MJ, Pearce AV, Farwell L et al. Association of DLG5 R30Q variant with inflammatory bowel disease. Eur J Hum Genet. 2005;13:835-9.

50. Noble CL, Nimmo ER, Drummond H, Smith L, Arnott ID, Satsangi J. DLG5 variants do not influence susceptibility to inflammatory bowel disease in the Scottish population. Gut. 2005;54:1416-20

51. Lakatos PL, Fischer S, Claes K et al., Hungarian IBD Study Group, Vermeire S, Lakatos L. DLG5 R30Q is not associated with inflammatory bowel disease in Hungarian IBD patients but predicts clinical response to steroids in Crohn's disease. Inflamm Bowel Dis. 2006;12:362-8.

52. Nemetz A, Kope A, Molnar T et al. Significant differences in the interleukin-1 beta and interleukin-1 receptor antagonist gene polymorphisms in Hungarian population with inflammatory bowel disease. Scand J Gastroenterol. 1999;34:175-9.

53. Carter MJ, di Giovine FS, Jones $\mathrm{S}$ et al. Association of the interleukin 1 receptor antagonist gene with ulcerative colitis in Northern European Caucasians. Gut. 2001;48:461-7.

54. Craggs A, West S, Curtis A et al. Absence of genetic association between IL-1RN and IL1B gene polymorphisms in ulcerative colitis and Crohn disease in multiple populations from northeast England. Scand J Gastroenterol. 2001;36:1173-8.

55. Plevy SE, Targan SR, Yang H, Fernandez D, Rotter JI, Toyoda H. Tumor necrosis factor microsatellites define a Crohn's disease associated haplotype on chromosome 6 . Gastroenterology. 1996;110:1053-60.

56. Waschke KA, Villani AC, Vermeire $S$ et al. Tumor necrosis factor receptor gene polymorphisms in Crohn's disease: association with clinical phenotypes. Am J Gastroenterol. 2005;100:1126-33. 


\section{PATHOGENESIS AND CLINICAL PRACTICE IN GASTROENTEROLOGY}

57. Yamazaki K, McGovern D, Ragoussis $\mathrm{J}$ et al. Single nucleotide polymorphisms in TNFSF15 confer susceptibility to Crohn's disease. Hum Mol Genet. 2005;14:3499-506.

58. Brant SR, Panhuysen CI, Nicolae D et al. MDR1 Ala893 polymorphism is associated with inflammatory bowel disease. Am J Hum Genet. 2003;73:1282-92.

59. Schwab M, Schaeffeler E, Marx C et al. Association between the C3435T MDR1 gene polymorphism and susceptibility for ulcerative colitis. Gastroenterology. 2003;124:26-33.

60. Ho GT, Nimmo ER, Tenesa A et al. Allelic variations of the multidrug resistance gene determine susceptibility and disease behaviour in ulcerative colitis. Gastroenterology. 2005;128:288-96.

61. Ho GT, Soranzo N, Nimmo ER et al. ABCB1/MDR1 gene determines susceptibility and phenotype in ulcerative colitis: discrimination of critical variants using a gene-wide haplotype tagging approach. Hum Mol Genet. 2006;15:797-805.

62. Urcelay E, Mendoza JL, Martin MC et al. MDR1 gene: susceptibility in Spanish Crohn's disease and ulcerative colitis patients. Inflamm Bowel Dis. 2006;12:33-7.

63. Fischer S, Lakatos PL, Lakatos L et al. The ATP-binding cassette transporter ABCG2 (BCRP) and $\mathrm{ABCB} 1$ (MDR1) variants are not associated with disease susceptibility and disease phenotype in Hungarian patients with inflammatory bowel diseases. Scand $\mathbf{J}$ Gastroenterol. 2007;42:726-33.

64. Hampe J, Franke A, Rosenstiel P et al. A genome wide association study of nonsynonymous SNPs identifies a susceptibility variant for Crohn disease in ATG16L1. Nat Genet. 2007;39:207-11

65. Schmid D, Dengjel J, Schoor O, Stevanovic S, Munz C. Autophagy in innate and adaptive immunity against intracellular pathogens. J Mol Med. 2006;84:194-202.

66. Prescott NJ, Fisher SA, Franke A et al. A nonsynonymous SNP in ATG16L1 predisposes to ileal Crohn's disease and is independent of CARD15 and IBD5. Gastroenterology. 2007;132:1665-71.

67. Cummings JR, Cooney R, Pathan S et al. Confirmation of the role of ATG1611 as a Crohn's disease susceptibility gene. Inflamm Bowel Dis. 2007; April 23 (Epub ahead of print).

68. Parkes M, Barrett JC, Prescott NJ et al.; the Wellcome Trust Case Control Consortium, Cardon L, Mathew CG. Sequence variants in the autophagy gene IRGM and multiple other replicating loci contribute to Crohn's disease susceptibility. Nat Genet. 2007; June 6 (Epub ahead of print)

69. Duerr RH, Taylor KD, Brant SR et al. A genome-wide association study identifies IL23R as an inflammatory bowel disease gene. Science. 2006;314:1461-63.

70. Tremelling M, Cummings F, Fisher SA et al. IL23R variation determines susceptibility but not disease phenotype in inflammatory bowel disease. Gastroenterology. 2007;132:165764.

71. Fraser Cummings JR, Ahmad T, Geremia A et al. Contribution of the novel inflammatory bowel disease gene IL23R to disease susceptibility and phenotype. Inflamm Bowel Dis. 2007; May 16 (Epub ahead of print).

72. Krynetski EY, Krynetskaia NF, Yanishevski Y, Evans WE. Methylation of mercaptopurine, thioguanine, and their nucleotide metabolites by heterologously expressed human thiopurine S-methyltransferase. Mol Pharmacol. 1995;47:1141-7.

73. Krynetski EY, Evans WE. Genetic polymorphism of thiopurine S-methyltransferase molecular mechanisms and clinical importance. Pharmacology. 2000;61:136-46.

74. Weinshilboum RM, Sladek SL. Mercaptopurine pharmacogenetics: monogenic inheritance of erythrocyte thiopurine methyltransferase activity. Am J Hum Genet. 1980;32:651-62.

75. Colombel JF, Ferrari N, Debuysere H et al. Genotypic analysis of thiopurine Smethyltransferase in patients with Crohn's disease and severe myelosuppression during azathioprine therapy. Gastroenterology. 2000;118:1025-30.

76. Saxon A, Shanahan F, Landers C, Ganz T, Targan S. A distinct subset of antineutrophil cytoplasmic antibodies is associated with inflammatory bowel disease. J Allergy Clin Immunol. 1990;86:202-10.

77. Rump JA, Scholmerich J, Gross V et al. A new type of perinuclear anti-neutrophil cytoplasmic antibody (p-ANCA) in active ulcerative colitis but not in Crohn's disease Immunobiology. 1990;181:406-13.

78. Bossuyt X. Serologic markers in inflammatory bowel disease. Clin Chem. 2006;52:171-81. 
79. Terjung B, Worman HJ. Anti-neutrophil antibodies in primary sclerosing cholangitis. Best Pract Res Clin Gastroenterol. 2001;15:629-42.

80. Terjung B, Bogsch F, Klein R et al. Diagnostic accuracy of atypical p-ANCA in autoimmune hepatitis using ROC- and multivariate regression analysis. Eur J Med Res. 2004;9:439-48.

81. Vidrich A, Lee J, James E, Cobb L, Targan S. Segregation of pANCA antigenic recognition by DNase treatment of neutrophils: ulcerative colitis, type 1 autoimmune hepatitis, and primary sclerosing cholangitis. J Clin Immunol. 1995;15:293-9.

82. Main J, McKenzie H, Yeaman GR et al. Antibody to Saccharomyces cerevisiae (bakers' yeast) in Crohn's disease. Br Med J. 1988;297:1105-6.

83. Quinton JF, Sendid B, Reumaux D et al. Anti-Saccharomyces cerevisiae mannan antibodies combined with antineutrophil cytoplasmic autoantibodies in inflammatory bowel disease: prevalence and diagnostic role. Gut. 1998;42:788-91.

84. Peeters M, Joossens S, Vermeire S, Vlietinck R, Bossuyt X, Rutgeerts P. Diagnostic value of anti-Saccharomyces cerevisiae and antineutrophil cytoplasmic autoantibodies in inflammatory bowel disease. Am J Gastroenterol. 2001;96:730-4.

85. Papp M, Istvan Altorjay I, Norman GL et al. Sero-reactivity to microbial components in Crohn's disease is associated with ileal involvement, non-inflammatory disease behaviour and NOD2/CARD15 genotype, but not with risk for surgery in a Hungarian cohort of IBD patient. Inflamm Bowel Dis. 2007; April 6 (Epub ahead of print).

86. Norman GL. Anti-Saccharomyces cerevisiae antibodies in inflammatory bowel disease. Clin Applied Immunol Rev. 2001;2:45-63.

87. Vermeire S, Joossens S, Peeters $M$ et al. Comparative study of ASCA (anti-Saccharomyces cerevisiae antibody) assays in inflammatory bowel disease. Gastroenterology. 2001;120:827-33.

88. Landers CJ, Cohavy O, Misra R et al. Selected loss of tolerance evidenced by Crohn's disease-associated immune responses to auto- and microbial antigens. Gastroenterology. 2002;123:689-99.

89. Zholudev A, Zurakowski D, Young W, Leichtner A, Bousvaros A. Serologic testing with ANCA, ASCA, and anti-OmpC in children and young adults with Crohn's disease and ulcerative colitis: diagnostic value and correlation with disease phenotype. Am J Gastroenterol. 2004;99:2235-41.

90. Sutton CL, Kim J, Yamane A et al. Identification of a novel bacterial sequence associated with Crohn's disease. Gastroenterology. 2000;119:23-31

91. Wei B, Huang T, Dalwadi H, Sutton CL, Bruckner D, Braun J. Pseudomonas fluorescens encodes the Crohn's disease-associated I2 sequence and T-cell superantigen. Infect Immun. 2002;70:6567-75.

92. Lodes MJ, Cong Y, Elson CO et al. Bacterial flagellin is a dominant antigen in Crohn disease. J Clin Invest. 2004;113:1296-306.

93. Targan SR, Landers CJ, Yang $\mathrm{H}$ et al. Antibodies to CBir1 flagellin define a unique response that is associated independently with complicated Crohn's disease. Gastroenterology. 2005;128:2020-8.

94. Lawrance IC, Hall A, Leong R, Pearce C, Murray K. A comparative study of goblet cell and pancreatic exocine autoantibodies combined with ASCA and pANCA in Chinese and Caucasian patients with IBD. Inflamm Bowel Dis. 2005;11:890-7.

95. Stocker W, Otte M, Ulrich S et al. Autoimmunity to pancreatic juice in Crohn's disease. Results of an autoantibody screening in patients with chronic inflammatory bowel disease. Scand J Gastroenterol Suppl. 1987;139:41-52.

96. Dotan I, Fishman S, Dgani Y et al. Antibodies against laminaribioside and chitobioside are novel serologic markers in Crohn's disease. Gastroenterology. 2006;131:366-78.

97. Ferrante M, Henckaerts L, Joossens $M$ et al. New serological markers in inflammatory bowel disease are associated with complicated disease behaviour. Gut. 2007;Apr 24 (Epub ahead of print).

98. Czaja AJ, Shums Z, Donaldson PT, Norman GL. Frequency and significance of antibodies to Saccharomyces cerevisiae inautoimmune hepatitis. Dig Dis Sci. 2004;49:611-18.

99. Reddy KR, Colombel JF, Poulain D, Krawitt EL. Anti-Saccharomyces cerevisiae antibodies in autoimmune liver disease. Am J Gastroenterol. 2001;96:252-3.

100. Vernier G, Sendid B, Poulain D, Colombel JF. Relevance of serologic studies in inflammatory bowel disease. Curr Gastroenterol Rep. 2004;6:482-7. 


\section{PATHOGENESIS AND CLINICAL PRACTICE IN GASTROENTEROLOGY}

101. Linskens RK, Mallant-Hent RC, Groothuismink ZM et al. Evaluation of serological markers to differentiate between ulcerative colitis and Crohn's disease: pANCA, ASCA and agglutinating antibodies to anaerobiccoccoid rods. Eur J Gastroenterol Hepatol. 2002;14:1013-18.

102. Koutroubakis IE, Petinaki E, Mouzas IA et al. Anti-Saccharomyces cerevisiae mannan antibodies and antineutrophil cytoplasmic autoantibodies in Greek patients with inflammatory bowel disease. Am J Gastroenterol. 2001;96:449-54.

103. Seibold F, Slametschka D, Gregor M, Weber P. Neutrophil autoantibodies: a genetic marker in primary sclerosing cholangitis and ulcerative colitis. Gastroenterology. 1994;107:532-6.

104. Shanahan F, Duerr RH, Rotter JI et al. Neutrophil autoantibodies in ulcerative colitis: familial aggregation and genetic heterogeneity. Gastroenterology. 1992;103:456-61.

105. Lee JC, Lennard-Jones JE, Cambridge G. Antineutrophil antibodies in familial inflammatory bowel disease. Gastroenterology. 1995;108:428-33.

106. Folwaczny C, Noehl N, Endres SP, Loeschke K, Fricke H. Antineutrophil and pancreatic autoantibodies in first-degree relatives of patients with inflammatory bowel disease. Scand $\mathbf{J}$ Gastroenterol. 1998;33:523-8.

107. Sendid B, Quinton JF, Charrier G et al. Anti-Saccharomyces cerevisiae mannan antibodies in familial Crohn's disease. Am J Gastroenterol. 1998;93:1306-10.

108. Seibold F, Stich O, Hufnagl R, Kamil S, Scheurlen M. Anti-Saccharomyces cerevisiae antibodies in inflammatory bowel disease: a family study. Scand J Gastroenterol. 2001;36:196-201.

109. Israeli E, Grotto I, Gilburd B et al. Anti-Saccharomyces cerevisiae and antineutrophil cytoplasmic antibodies as predictors of inflammatory bowel disease. Gut. 2005;54:1232-6.

110. Joossens S, Reinisch W, Vermeire S et al. The value of serologic markers in indeterminate colitis: a prospective follow-up study. Gastroenterology. 2002;122:1242-7.

111. Joossens S, Colombel JF, Landers C et al. Anti-outer membrane of porin C and anti-I2 antibodies in indeterminate colitis. Gut. 2006;55:1667-9.

112. Lichtenstein GR, Carroll S, Eggleston L, Neri B, Lois A. Validation of a computer-aided analysis of inflammatory bowel disese (IBD) serologic markers: a novel method to improve the accuracy of predicting IBD, Crohn's disease (CD), and ulcerative colitis (UC). Gastroenterology. 2007;132:A175 (S1106).

113. Sandborn WJ, Landers CJ, Tremaine WJ, Targan SR. Association of antineutrophil cytoplasmic antibodies with resistance to treatment of left-sided ulcerative colitis: results of a pilot study. Mayo Clin Proc. 1996;71:431-6.

114. Sandborn WJ, Landers CJ, Tremaine WJ, Targan SR. Antineutrophil cytoplasmic antibody correlates with chronic pouchitis after ileal pouch-anal anastomosis. Am J Gastroenterol. 1995;90:740-7.

115. Vasiliauskas EA, Plevy SE, Landers CJ et al. Perinuclear antineutrophil cytoplasmic antibodies in patients with Crohn's disease define a clinical subgroup. Gastroenterology. 1996;110:1810-19.

116. Vasiliauskas EA, Kam LY, Karp LC, Gaiennie J, Yang H, Targan SR. Marker antibody expression stratifies Crohn's disease into immunologically homogeneous subgroups with distinct clinical characteristics. Gut. 2000;47:487-96.

117. Klebl FH, Bataille F, Bertea CR et al. Association of perinuclear antineutrophil cytoplasmic antibodies and anti-Saccharomyces cerevisiae antibodies with Vienna classification subtypes of Crohn's disease. Inflamm Bowel Dis. 2003;9:302-7.

118. Vermeire S, Peeters M, Vlietinck R et al. Anti-Saccharomyces cerevisiae antibodies (ASCA), phenotypes of IBD, and intestinal permeability: a study in IBD families. Inflamm Bowel Dis. 2001; 7:8-15.

119. Walker LJ, Aldhous MC, Drummond HE et al. Anti-Saccharomyces cerevisiae antibodies (ASCA) in Crohn's disease are associated with disease severity but not NOD2/CARD15 mutations. Clin Exp Immunol. 2004;135:490-6.

120. Mow WS, Vasiliauskas EA, Lin YC et al. Association of antibody responses to microbial antigens and complications of small bowel Crohn's disease. Gastroenterology. 2004;126:414-24.

121. Desir B, Amre DK, Lu SE et al. Utility of serum antibodies in determining clinical course in pediatric Crohn's disease. Clin Gastroenterol Hepatol. 2004;2:139-46. 
122. Dubinsky MC, Lin YC, Dutridge D et al.; Western Regional Pediatric IBD Research Alliance. Serum immune responses predict rapid disease progression among children with Crohn's disease: immune responses predict disease progression. Am J Gastroenterol. 2006;101:360-7.

123. Sandborn WJ, Landers CJ, Tremaine WJ, Targan SR. Association of antineutrophil cytoplasmic antibodies with resistance to treatment of left-sided ulcerative colitis: results of a pilot study. Mayo Clin Proc. 1996;71:431-6.

124. Arnott ID, Landers CJ, Nimmo EJ et al. Sero-reactivity to microbial components in Crohn's disease is associated with disease severity and progression, but not NOD2/ CARD15 genotype. Am J Gastroenterol. 2004;99:2376-84.

125. Oshitani N, Hato F, Matsumoto T et al. Decreased anti-Saccharomyces cerevisiae antibody titer by mesalazine in patients with Crohn's disease. J Gastroenterol Hepatol. 2000;15:1400-3.

126. Teml A, Kratzer V, Schneider B et al. Anti-Saccharomyces cerevisiae antibodies: a stable marker for Crohn's disease during steroid and 5-aminosalicylic acid treatment. Am J Gastroenterol. 2003;98:2226-31.

127. Esters N, Vermeire S, Joossens S et al.; Belgian Group of Infliximab Expanded Access Program in Crohn's Disease. Serological markers for prediction of response to anti-tumor necrosis factor treatment in Crohn's disease. Am J Gastroenterol. 2002;97:1458-62.

128. Mow WS, Landers CJ, Steinhart AH et al. High-level serum antibodies to bacterial antigens are associated with antibiotic-induced clinical remission in Crohn's disease: a pilot study. Dig Dis Sci. 2004;49:1280-6.

129. Gabay C, Kushner I. Acute-phase proteins and other systemic responses to inflammation. N Engl J Med. 1999;340:448-54.

130. Tillet WS, Francis T. Serological reactions in pneumonia with a non-protein somatic fraction of the pneumococcus. J Exp Med. 1930;52:561-71.

131. Tall AR. C-reactive protein reassessed. N Engl J Med. 2004;350:1450-2.

132. Ballou SP, Kushner I. C-reactive protein and the acute phase response. Adv Intern Med. 1992;37:313-36.

133. Beattie RM, Walker-Smith JA, Murch SH. Indications for investigation of chronic gastrointestinal symptoms. Arch Dis Child. 1995;73:354-5.

134. Saverymuttu SH, Hodgson HJ, Chadwick VS, Pepys MB. Differing acute phase responses in Crohn's disease and ulcerative colitis. Gut. 1986;27:809-13.

135. Willot S, Vermeire S, Ohresser $M$ et al. No association between C-reactive protein gene polymorphisms and decrease of $\mathrm{C}$-reactive protein serum concentration after infliximab treatment in Crohn's disease. Pharmacogenet Genom. 2006;16:37-42.

136. Meuwis MA, Marianne Fillet M, Geurts P et al. Biomarker discovery for inflammatory bowel disease, using proteomic serum profiling. Biochem Pharmacol. 2007;73:1422-33.

137. Tibble J, Teahon K, Thjodleifsson B et al. A simple method for assessing intestinal inflammation in Crohn's disease. Gut. 2000;47:506-13.

138. Sugi K, Saitoh O, Hirata I, Katsu K. Fecal lactoferrin as a marker for disease activity in inflammatory bowel disease: comparison with other neutrophilderived proteins. Am J Gastroenterol. 1996;91:927-34.

139. Roseth AG, Schmidt PN, Fagerhol MK. Correlation between faecal excretion of indium111-labelled granulocytes and calprotectin, a granulocyte marker protein, in patients with inflammatory bowel disease. Scand J Gastroenterol. 1999;34:50-4.

140. Foell D, Kucharzik T, Kraft M et al. Neutrophil derived human S100A12 (EN-RAGE) is strongly expressed during chronic active inflammatory bowel disease. Gut. 2003;52:847-53.

141. Walker TR, Land ML, Kartashov A et al. Fecal lactoferrin is a sensitive and specific marker of disease activity in children and young adults with inflammatory bowel disease. $\mathbf{J}$ Pediatr Gastroenterol Nutr. 2007;44:414-22.

142. Shine B, Berghouse L, Jones JE, Landon J. C-reactive protein as an aid in the differentiation of functional and inflammatory bowel disorders. Clin Chim Acta. 1985;148:105-9.

143. Poullis AP, Zar S, Sundaram KK et al. A new, highly sensitive assay for Creactive protein can aid the differentiation of inflammatory bowel disorders from constipation- and diarrhoea-predominant functional bowel disorders. Eur J Gastroenterol Hepatol. 2002;14:409-12. 


\section{PATHOGENESIS AND CLINICAL PRACTICE IN GASTROENTEROLOGY}

144. Fagerberg UL, Loof L, Myrdal U, Hansson LO, Finkel Y. Colorectal inflammation is well predicted by fecal calprotectin in children with gastrointestinal symptoms. J Pediatr Gastroenterol Nutr. 2005;40:450-5.

145. Thjodleifsson B, Sigthorsson G, Cariglia N et al. Subclinical intestinal inflammation: an inherited abnormality in Crohn's disease relatives? Gastroenterology. 2003;124:1728-37.

146. von Roon AC, Karamountzos L, Purkayastha S et al. Diagnostic precision of fecal calprotectin for inflammatory bowel disease and colorectal malignancy. Am J Gastroenterol. 2007;102:803-13.

147. Danesh J, Wheeler JG, Hirschfield GM et al. C-reactive protein and other circulating markers of inflammation in the prediction of coronary heart disease. $\mathrm{N}$ Engl $\mathrm{J}$ Med. 2004;350:1387-97.

148. Bataille R, Boccadoro M, Klein B, Durie B, Pileri A. C-reactive protein and beta-2 microglobulin produce a simple and powerful myeloma staging system. Blood. 1992;80:733-7.

149. Tromm A, Tromm CD, Huppe D, Schwegler U, Krieg M, May B. Evaluation of different laboratory tests and activity indices reflecting the inflammatory activity of Crohn's disease. Scand J Gastroenterol. 1992;27:774-8.

150. Sachar DB, Smith H, Chan S, Cohen LB, Lichtiger S, Messer J. Erythrocytic sedimentation rate as a measure of clinical activity in inflammatory bowel disease. J Clin Gastroenterol. 1986;8:647-50.

151. Fagan EA, Dyck RF, Maton PN et al. Serum levels of C-reactive protein in Crohn's disease and ulcerative colitis. Eur J Clin Invest. 1982;12:351-9.

152. Solem CA, Loftus EV Jr, Tremaine WJ, Harmsen WS, Zinsmeister AR, Sandborn WJ Correlation of C-reactive protein (CRP) with clinical, radiographic, and endoscopic activity in inflammatory bowel disease (IBD). Inflamm Bowel Dis. 2005;11:707-12.

153. Florin TH, Paterson EW, Fowler EV, Radford-Smith GL. Clinically active Crohn's disease in the presence of a low C-reactive protein. Scand J Gastroenterol. 2006;41:306-11.

154. Brignola C, Campieri M, Bazzocchi G, Farruggia P, Tragnone A, Lanfranchi GA. A laboratory index for predicting relapse in asymptomatic patients with Crohn's disease. Gastroenterology. 1986;91:1490-4

155. Boirivant M, Leoni M, Tariciotti D, Fais S, Squarcia O, Pallone F. The clinical significance of serum C reactive protein levels in Crohn's disease. Results of a prospective longitudinal study. J Clin Gastroenterol. 1988;10:401-5.

156. Consigny Y, Modigliani R, Colombel JF, Dupas JL, Lemann M, Mary JY (GETAID). A simple biological score for predicting low risk of short-term relapse in Crohn's disease. Inflamm Bowel Dis. 2006;12:551-7.

157. Travis SP, Farrant JM, Ricketts $C$ et al. Predicting outcome in severe ulcerative colitis. Gut. 1996;38:905-10.

158. Zilberman L, Maharshak N, Arbel Y et al. Correlated expression of high-sensitivity Creactive protein in relation to disease activity in inflammatory bowel disease: lack of differences between Crohn's disease and ulcerative colitis. Digestion. 2006;73:205-9.

159. Tibble JA, Sigthorsson G, Bridger S, Fagerhol MK, Bjarnason I. Surrogate markers of intestinal inflammation are predictive of relapse in patients with inflammatory bowel disease. Gastroenterology. 2000;119:15-22.

160. Costa F, Mumolo MG, Ceccarelli L et al. Calprotectin is a stronger predictive marker of relapse in ulcerative colitis than in Crohn's disease. Gut. 2005;54:364-8

161. D'Inca R, Dal Pont E, Di Leo V et al. Calprotectin and lactoferrin in the assessment of intestinal inflammation and organic disease. Int J Colorectal Dis. 2007;22:429-37.

162. Roseth AG, Aadland E, Grzyb K. Normalization of faecal calprotectin: a predictor of mucosal healing in patients with inflammatory bowel disease. Scand J Gastroenterol. 2004;39:1017-20.

163. Louis E, Vermeire S, Rutgeerts $P$ et al. A positive response to infliximab in Crohn disease: association with a higher systemic inflammation before treatment but not with -308 TNF gene polymorphism. Scand J Gastroenterol. 2002;37:818-24.

164. Schreiber S, Rutgeerts P, Fedorak RN et al; CDP870 Crohn's Disease Study Group. CDP870 Crohn's Disease Study Group. A randomized, placebo-controlled trial of certolizumab pegol (CDP870) for treatment of Crohn's disease. Gastroenterology. 2005;129:807-18. 
165. Lémann M, Mary JY, Colombel JF et al. A randomized, double-blind, controlled withdrawal trial in Crohn's disease patients in long-term remission on azathioprine. Gastroenterology. 2005;128:1812-18.

166. Orlando A, Modesto I, Castiglione F et al. The role of calprotectin in predicting endoscopic post-surgical recurrence in asymptomatic Crohn's disease: a comparison with ultrasound. Eur Rev Med Pharmacol Sci. 2006;10:17-22.

167. Scarpa M, D'Inca R, Basso D et al. Fecal lactoferrin and calprotectin after ileocolonic resection for Crohn's disease. Dis Colon Rectum. 2007;50:861-9. 